\title{
Molecular features of triple negative breast cancer cells by genome-wide gene expression profiling analysis
}

\author{
MASATO KOMATSU $^{1,2^{*}}$, TETSURO YOSHIMARU $^{1 *}$, TAISUKE MATSUO $^{1}$, KAZUMA KIYOTANI $^{1}$, \\ YASUO MIYOSHI ${ }^{3}$, TOSHIHITO TANAHASHI ${ }^{4}$, KAZUHITO ROKUTAN ${ }^{4}$, RUI YAMAGUCHI $^{5}$, \\ AYUMU SAITO $^{6}$, SEIYA IMOTO $^{6}$, SATORU MIYANO ${ }^{6}$, YUSUKE NAKAMURA ${ }^{7}$, \\ MITSUNORI SASA $^{8}$, MITSUO SHIMADA ${ }^{2}$ and TOYOMASA KATAGIRI ${ }^{1}$
}

\begin{abstract}
${ }^{1}$ Division of Genome Medicine, Institute for Genome Research, The University of Tokushima; ${ }^{2}$ Department of Digestive and Transplantation Surgery, The University of Tokushima Graduate School; ${ }^{3}$ Department of Surgery, Division of Breast and Endocrine Surgery, Hyogo College of Medicine, Hyogo 663-8501; ${ }^{4}$ Department of Stress Science, Institute of Health Biosciences, The University of Tokushima Graduate School, Tokushima 770-8503; Laboratories of ${ }^{5}$ Sequence Analysis, ${ }^{6}$ DNA Information Analysis and ${ }^{7}$ Molecular Medicine, Human Genome Center, Institute of Medical Science, The University of Tokyo, Tokyo 108-8639; ${ }^{8}$ Tokushima Breast Care Clinic, Tokushima 770-0052, Japan
\end{abstract}

Received September 22, 2012; Accepted November 6, 2012

DOI: $10.3892 /$ ijo.2012.1744

\begin{abstract}
Triple negative breast cancer (TNBC) has a poor outcome due to the lack of beneficial therapeutic targets. To clarify the molecular mechanisms involved in the carcinogenesis of TNBC and to identify target molecules for novel anticancer drugs, we analyzed the gene expression profiles of 30 TNBCs as well as 13 normal epithelial ductal cells that were purified by laser-microbeam microdissection. We identified 301 and 321 transcripts that were significantly upregulated and downregulated in TNBC, respectively. In particular, gene expression profile analyses of normal human vital organs allowed us to identify 104 cancer-specific genes, including those involved in breast carcinogenesis such as NEK2, PBK and MELK. Moreover, gene annotation enrichment analysis revealed prominent gene subsets involved in the cell cycle, especially mitosis. Therefore, we focused on cell cycle regulators, asp (abnormal spindle) homolog, microcephaly-associated (Drosophila) (ASPM) and centromere protein K (CENPK) as novel therapeutic targets for TNBC. Small-interfering RNA-mediated knockdown of their expression significantly attenuated TNBC cell viability due to G1 and G2/M cell cycle arrest. Our data will provide a better understanding of the
\end{abstract}

Correspondence to: Dr Toyomasa Katagiri, Division of Genome Medicine, Institute of Genome Research, The University of Tokushima, 3-18-15 Kuramoto-cho, Tokushima 770-8503, Japan

E-mail: tkatagi@genome.tokushima-u.ac.jp

${ }^{*}$ Contributed equally

Key words: triple negative breast cancer, expression profiling, molecular targets carcinogenesis of TNBC and could contribute to the development of molecular targets as a treatment for TNBC patients.

\section{Introduction}

Breast cancer is one of the most common solid malignant tumors among women worldwide. Breast cancer is a heterogeneous disease that is currently classified based on the expression of estrogen receptor (ER), progesterone receptor (PgR), and the human epidermal growth factor receptor 2 (HER2) $(1,2)$. For patients with ER- or PgR-positive breast cancer, approximately five years of adjuvant endocrine therapy reduces the annual breast cancer death rate by approximately $30 \%$ (3). The addition of HER2-antagonist trastuzumab to adjuvant chemotherapy has improved the prognosis of HER2-positive breast cancer patients (4-6). In contrast, triple negative breast cancer (TNBC), defined as tumors that are negative for ER, PgR and HER2 overexpression, accounts for at least 15-20\% of all breast cancers, and the prognosis for TNBC patients is poor because of its propensity for recurrence and metastasis and a lack of clinically-established targeted therapies $(7,8)$. Therefore, only neoadjuvant chemotherapy with conventional cytotoxic agents yield an excellent outcome for TNBC patients who have a complete pathological response, but the outcome for the vast majority with residual disease after chemotherapy is relatively poor compared to non-TNBC patients $(6,7)$. Thus, because the heterogeneity of breast cancer makes it difficult to treat many subtypes, including TNBC, the molecular mechanisms of the carcinogenesis of TNBC must be elucidated to develop novel molecular-targeted therapies that improve the clinical outcome of TNBC patients.

Current 'omics' technology including DNA microarray analysis can provide very helpful information that can be used to categorize the characteristics of various malignant tumors and identify genes that may be applicable for the develop- 
ment of novel molecular targets for therapeutic modalities (9). To this end, we analyzed the gene expression profile of 30 TNBC cells and normal breast ductal cells that were purified by laser-microbeam microdissection and identified a number of cancer-specific genes that might contribute to the carcinogenesis of TNBC. TNBC gene expression profiling analysis can provide comprehensive information on the molecular mechanism underlying the carcinogenesis of TNBC and possibly lead to the development of novel effective therapies.

\section{Materials and methods}

Clinical samples and cell lines. A total of 48 TNBC (18 cases did not entry DNA microarray analysis) and 13 normal mammary tissues were obtained with informed consent from patients who were treated at Tokushima Breast Care Clinic, Tokushima, Japan. This study, as well as the use of all clinical materials described above, was approved by the Ethics Committee of The University of Tokushima. Clinical information was obtained from medical records and tumors were diagnosed as triple-negative by pathologists when immunohistochemical staining was ER-negative, PR-negative, and HER2 (0 or 1+). The clinicopathological features of each patient are summarized in Table I. Samples were immediately embedded in TissueTek OCT compound (Sakura, Tokyo, Japan), frozen, and stored at $-80^{\circ} \mathrm{C}$. Human TNBC cell lines MDA-MB-231, BT-20, BT-549, HCC1143, and HCC1937 were purchased from the American Type Culture Collection (ATCC, Rockville, MD, USA). The human normal breast epithelial cell line, MCF10A, was purchased from Cambrex Bioscience, Inc. All cells were cultured under the conditions recommended by their respective depositors.

Laser-microbeam microdissection (LMM), RNA extraction, RNA amplification, and hybridization. Frozen specimens were serially sectioned in $8-\mu \mathrm{m}$ slices with a cryostat (Leica, Herborn, Germany) and stained with hematoxylin and eosin to define the analyzed regions. We purified 48 TNBC and 13 normal ductal cells using the LMM system (Carl Zeiss, Jena, Germany) according to the manufacturer's instructions. Dissected cancer and normal ductal cells were dissolved in RLT lysis buffer (Qiagen, Valencia, CA, USA) containing 1\% $\beta$-mercaptoethanol. The extracted total RNA was purified with an RNeasy Mini kit (Qiagen) according to the manufacturer's instructions. For RNA amplification and labeling, we used an Agilent Low-Input QuickAmp labeling kit according to the manufacturer's instructions. Briefly, $100 \mathrm{ng}$ of total RNA from each sample was amplified using T7 RNA polymerase with simultaneous Cy3-labeled CTP incorporation. Then, $2 \mu \mathrm{g}$ of Cy3-labeled cRNA was fragmented, hybridized onto the Agilent Whole Human Genome Microarray 4x44K slide (Agilent Technologies, Palo Alto, CA, USA) and then incubated with rotation at $65^{\circ} \mathrm{C}$ for $18 \mathrm{~h}$. Then slides were washed and scanned by the Agilent Microarray scanner system in an ozone protection fume hood.

Microarray analysis. The features of scanned image files containing the Cy3-fluorescence signals of the hybridized Agilent Microarrays were extracted using the Agilent Feature
Extraction (version 9.5) (Agilent Technologies). The data were analyzed using GeneSpring (version 11.5). We normalized the microarray data across all chips and genes by quantile normalization, and baseline transformed the signal values to the median in all samples. Finally, we performed quality control and filtering steps based on flags and expression levels. To identify genes that were significantly alternated between TNBC and normal ductal cells the mean signal intensity values in each analysis were compared. In this experiment, we applied Mann-Whitney (unpaired) t-test and random permutation test 10,000 times for each comparison and adjusted for multiple comparisons using the Benjamini Hochberg false discovery rate (FDR). Gene expression levels were considered significantly different when the FDR (corrected P-value) $<5 \times 10^{-4}$ (when comparing normal ductal cells and TNBC) and the fold change was $\geq 5.0$. Data from this microarray analysis has been submitted to the NCBI Gene Expression Omnibus (GEO) archive as series GSE38959.

Functional gene annotation clustering. The Database for Annotation, Visualization and Integrated Discovery (DAVID 6.7) was approved to detect functional gene annotation clusters based on gene expression profiling by gene annotation enrichment analysis (http://david.abcc.ncifcrf.gov/) (10,11). The clusters from the gene annotation enrichment analysis were selected in this study based on a previous report (12).

Quantitative reverse transcription-PCR ( $q R T-P C R)$ analysis. Total RNA was extracted from each TNBC cell line and clinical sample using an RNeasy mini kit (Qiagen) according to the manufacturer's instructions. Purified RNA from each clinical sample and cell line, as well as poly-A RNA from normal human heart, lung, liver, and kidney (Takara, Otsu, Japan) was reverse transcribed for single-stranded cDNA using oligo(dT $)_{12-18}$ primers with Superscript II reverse transcriptase (Invitrogen, Life Technologies, Carlsbad, CA, USA). qRT-PCR analysis was performed using an ABI PRISM 7500 Real-Time PCR system (Applied Biosystems, Life Technologies, Carlsbad, CA, USA) and SYBR Premix Ex Taq (Takara) according to the manufacturer's instructions. The PCR primer sequences were as follows: 5'-GCAGGTCTCC TTTCCTTTGCT-3' and 5'-CTCGGCCTTCTTTGAGT GGT-3' for ASPM; 5'-CACTCACCGATTCAAATG CTC-3' and 5'-ACCACCGTTGTTCCCTTTCT-3' for CENPK; 5'-AAC TTAGAGGTGGGGAGCAG-3' and 5'-CACAACCATGCC TTACTTTATC-3' for $\beta 2$ microglobulin $(\beta 2-M G)$ as a quantitative control.

Gene-silencing effect by RNA interference. Targeted sequences for $A S P M$ and $C E N P K$ were determined using an siRNA Targeted Finder (Applied Biosystems, Life Technologies; http://www.ambion.com/techlib/misc/siRNA_finder.html). The siRNA targeting sequences were 5'-CATACAGAAGT GCGAGAAA-3' for ASPM, 5'-CTCAGTCAATGGC AGAAAA-3' for CENPK and 5'-GCAGCACGACTTCT TCAAG-3' for EGFP as a control siRNA. Human TNBC cell lines, HCC1937, MDA-MB-231 and BT-20, were plated at a density of $1 \times 10^{4}$ cells per well in 12-wells for the MTT assay and $3 \times 10^{4}$ cells per well in 6-well plates for flow cytometry and RT-PCR analyses. Cells were transfected with $16.6 \mathrm{nM}$ 
Table I. Clinicopathological features of 48 TNBC patients.

\begin{tabular}{|c|c|c|c|c|c|c|c|}
\hline ID & Age & Histology & TNM & Stage & ER/PgR/HER2 & Microarray & RT-PCR \\
\hline 1 & 44 & Papillo-tubular & T0N3M1 & IV & $-/-/ 0$ & Done & Done \\
\hline 8 & 79 & DCIS & T1N0M0 & I & $-/-/ 0$ & Not done & Done \\
\hline 10 & 57 & Papillo-tubular & T1N0M0 & I & $-/-/ 1+$ & Not done & Done \\
\hline 19 & 63 & Solid-tubular & T1N0M0 & I & $-/-/ 0$ & Not done & Done \\
\hline 27 & 60 & Solid-tubular & T2N1M0 & II & $-/-/ 0$ & Done & Done \\
\hline 42 & 59 & Solid-tubular & T2N0M0 & II & $-/-/ 0$ & Not done & Done \\
\hline 44 & 79 & Papillo-tubular & Recurrence & - & $-/-/ 1+$ & Not done & Done \\
\hline 53 & 55 & Papillo-tubular & T1N0M0 & I & $-/-/ 0$ & Not done & Done \\
\hline 54 & 77 & Solid-tubular & T1N1M0 & II & $-/-/ 0$ & Not done & Done \\
\hline 56 & 28 & Scirrhous & T2N1M0 & II & $-/-/ 0$ & Done & Done \\
\hline 57 & 58 & Solid-tubular & T1N1M0 & II & $-/-/ 0$ & Not done & Done \\
\hline 60 & 54 & Solid-tubular & T2N1M0 & II & $-/-/ 0$ & Done & Done \\
\hline 64 & 60 & Papillo-tubular & T2N0M0 & II & $-/-/ 0$ & Not done & Done \\
\hline 66 & 59 & Special type & T2N1M0 & II & $-/-/ 0$ & Not done & Done \\
\hline 78 & 45 & Solid-tubular & T2N1M0 & II & $-/-/ 0$ & Done & Done \\
\hline 89 & 44 & Papillo-tubular & Recurrence & - & $-/-/ 0$ & Not done & Done \\
\hline 95 & 60 & Solid-tubular & T1N0M0 & I & $-/-/ 0$ & Not done & Done \\
\hline 101 & 60 & Scirrhous & T2N1M0 & II & $-/-/ 0$ & Not done & Done \\
\hline 110 & 77 & Scirrhous & T2N1M0 & II & $-/-/ 1+$ & Not done & Done \\
\hline 116 & 70 & Solid-tubular & T2N1M0 & II & $-/-/ 0$ & Done & Done \\
\hline 155 & 36 & Solid-tubular & T1N1M0 & II & $-/-/ 0$ & Done & Done \\
\hline 225 & 49 & Papillo-tubular & T2N1M0 & II & $-/-/ 1+$ & Not done & Done \\
\hline 252 & 49 & Solid-tubular & T2N1M0 & II & $-/-/ 1+$ & Done & Done \\
\hline 253 & 49 & Scirrhous & T2N1M0 & II & $-/-/ 0$ & Done & Done \\
\hline 265 & 80 & Scirrhous & T1N1M0 & II & $-/-/ 0-1+$ & Done & Done \\
\hline 313 & 53 & Scirrhous & T3N2M0 & III & $-/-/ 0$ & Done & Done \\
\hline 337 & 42 & Solid-tubular & T2N1M0 & II & $-/-/ 1+$ & Done & Done \\
\hline 359 & 55 & Papillo-tubular & T2N0M0 & II & $-/-/ 0$ & Done & Done \\
\hline 362 & 37 & Papillo-tubular & $\mathrm{T} 2 \mathrm{~N} 1 \mathrm{M} 0$ & II & $-/-/ 0$ & Done & Done \\
\hline 363 & 69 & Papillo-tubular & T2N0M0 & II & $-/-/ 0$ & Done & Done \\
\hline 366 & 61 & Special type & T2N1M0 & II & $-/-/ 0-1+$ & Done & Done \\
\hline 384 & 32 & Papillo-tubular & T3N0M0 & II & $-/-/ 0$ & Done & Done \\
\hline 392 & 46 & Papillo-tubular & T1N1M0 & II & $-/-/ 0$ & Done & Done \\
\hline 414 & 60 & Papillo-tubular & T2N1M0 & II & $-/-/ 1+$ & Not done & Done \\
\hline 415 & 54 & Solid-tubular & T2N0M0 & II & $-/-/ 1+$ & Done & Done \\
\hline 420 & 41 & Solid-tubular & T3N0M0 & II & $-/-/ 0$ & Done & Done \\
\hline 423 & 70 & Solid-tubular & T2N0M0 & II & $-/-/ 0$ & Done & Done \\
\hline 438 & 63 & Solid-tubular & T3N0M0 & II & $-/-/ 0$ & Done & Done \\
\hline 445 & 39 & Solid-tubular & T2N1M0 & II & $-/-/ 0$ & Done & Done \\
\hline 453 & 50 & Solid-tubular & T2N1M0 & II & $-/-/ 0$ & Done & Done \\
\hline 481 & 59 & Solid-tubular & T3N1M0 & III & $-/-/ 0$ & Done & Done \\
\hline 528 & 55 & Solid-tubular & $\mathrm{T} 2 \mathrm{~N} 1 \mathrm{M} 0$ & II & $-/-/ 0$ & Done & Done \\
\hline 535 & 58 & Solid-tubular & T2N1M0 & II & $-/-/ 0$ & Not done & Done \\
\hline 553 & 71 & Solid-tubular & T0N1M0 & II & $-/-/ 1+$ & Not done & Done \\
\hline 558 & 56 & Solid-tubular & T2N1M0 & II & $-/-/ 0$ & Done & Done \\
\hline 562 & 64 & Scirrhous & T2N0M0 & II & $-/-/ 0$ & Done & Done \\
\hline 566 & 52 & Solid-tubular & T3N1M0 & III & $-/-/ 0$ & Done & Done \\
\hline 651 & 45 & Scirrhous & T2N1M0 & II & $-/-/ 0$ & Done & Done \\
\hline
\end{tabular}

DCIS, ductal carcinoma in situ; papillo-tubular, papillo-tubular adenocarcinoma; solid-tubular, solid-tubular adenocarcinoma; scirrhous, scirrhous carcinoma; special type ID 66, adenocarcinoma with squamous cell carcinoma; ID 366, osseous metaplasia; case 44, axillary lymph node metastasis was diagnosed 8 months after the first surgery followed by the dissection of metastatic lymph nodes; case 89 , local recurrence in residual breast occurred after 2 years of the first surgery followed by a lumpectomy. All information was judged according to the General Rules for Clinical and Pathological Recording of Breast Cancer (The Japanese Breast Cancer Society). T, tumor stage; N, lymph node metastasis status; M, distant metastasis. 


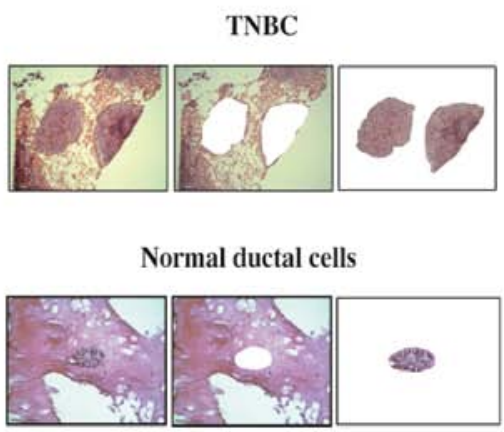

B

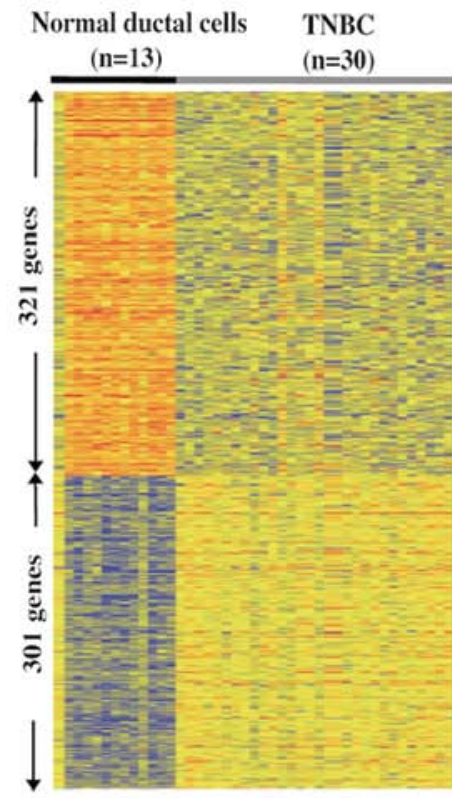

C

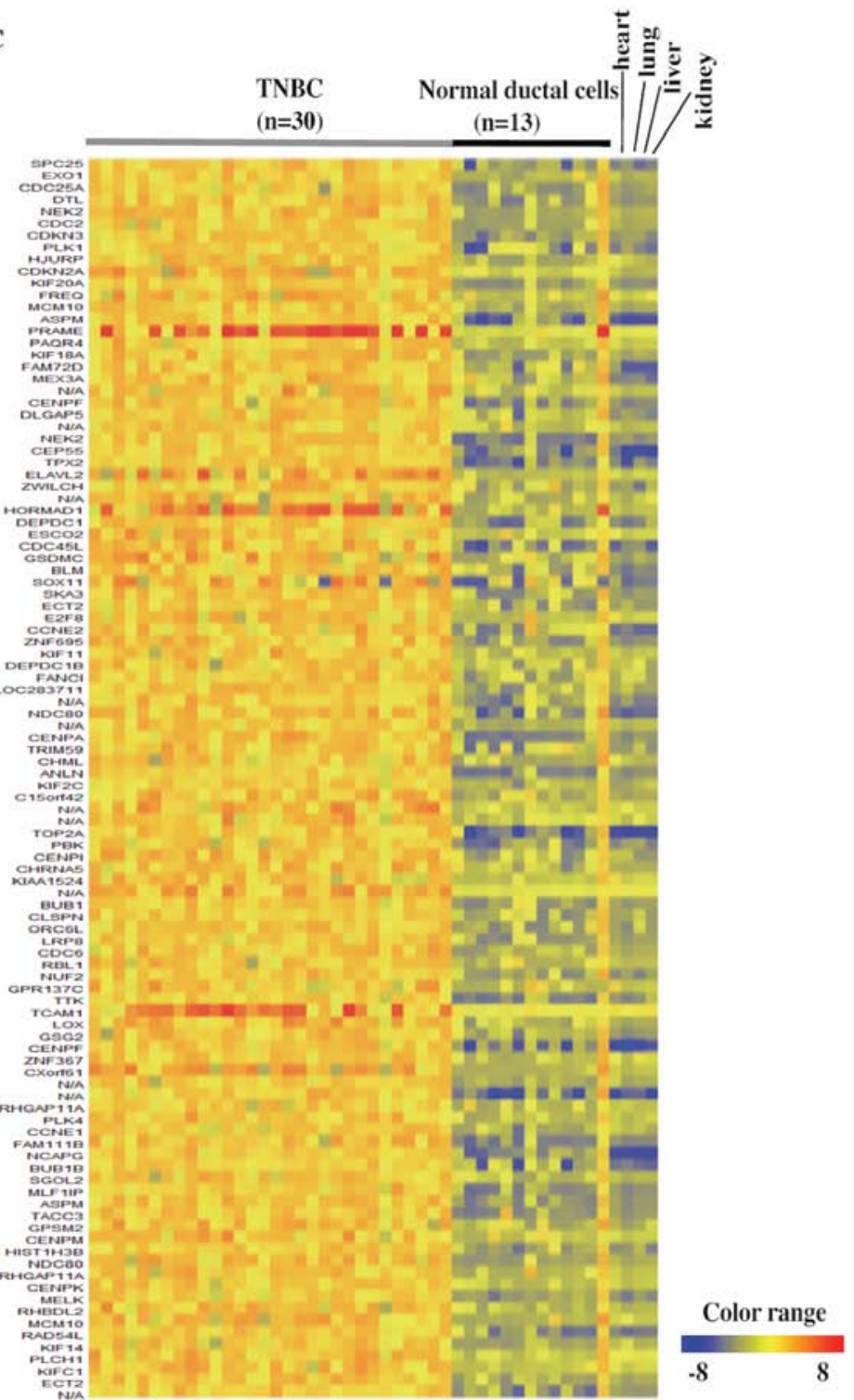

Figure 1. Purification of TNBC cells or ductal epithelial cells from normal ducts by means of microdissection and TNBC gene expression profiling. (A) Representative images of purified cancer cells and normal ductal epithelial cells from TNBC. Pre-microdissected (left lane), post-microdissected (middle lane) and microdissected cells (right lane) are shown after hematoxylin and eosin staining. (B) Heat-map image representing 622 genes that were significantly upregulated or downregulated $>5$-fold in TNBC. (C) Heat-map showing upregulated genes compared with normal ductal cells with no expression in normal organs including the heart, lung, liver and kidney.

of each siRNA using Lipofectamine RNAiMAX Reagent (Invitrogen). To evaluate the gene-silencing effects of the siRNAs by qRT-PCR, total RNA was extracted from the siRNA-transfected cells as described above after the indicated times. The following specific qRT-PCR primer sets were used: 5'-CGGAAAAGAAAGAGCGATGG-3' and 5'-ACCACCAAGTGAAGCCCTGT-3' for ASPM and 5'-GG GTGCCATCATTTTCTGGT-3' and 5'-CCACCGTTGTT CCCTTTCTAAG-3' for CENPK. To evaluate cell viability, the MTT assay was performed using the cell counting kit- 8 reagent (Dojindo, Kumamoto, Japan) according to the manufacturer's instructions. Absorbance at $450 \mathrm{~nm}$ was measured with a micro-plate reader infinite 200 (Tecan, Männedorf, Switzerland). These experiments were performed in triplicate.
Colony formation assay. Vector-based shRNAs and the psiU6BX3 expression system were constructed as previously described (13). The shRNA target sequences were the same as those of the siRNA oligonucleotides. The DNA sequences of all constructs were confirmed by DNA sequencing. BT-20 and MDA-MB-231 cells were plated in 10-cm dishes (1X10 ${ }^{6}$ cells/dish) and transfected with $6 \mu \mathrm{g}$ of psiU6BX3.0$A S P M$ or psiU6BX3.0-CENPK and psiU6BX3.0-EGFP as a control using Fugene-6 (Roche, Basel, Switzerland) according to the manufacturer's instructions. Forty-eight hours after transfection, cells were re-seeded for a colony formation assay $\left(5.0 \times 10^{5}\right.$ cells $/ 10-\mathrm{cm}$ dish) and RT-PCR $\left(5.0 \times 10^{5}\right.$ cells $/ 10-\mathrm{cm}$ dish). We selected psiU6BX3.0-transfected cells using selection medium containing $0.6 \mathrm{mg} / \mathrm{ml}$ of neomycin for BT-20 cells and $1.4 \mathrm{mg} / \mathrm{ml}$ for MDA-MB-231 cells. Total 
RNA was extracted from the cells after a 7-day incubation with neomycin, and then the knockdown effects of the siRNAs were examined by qRT-PCR. The specific primer sets for quantitative RT-PCR were the same as those for the siRNA oligonucleotides. Nineteen days after transfection, the cells were fixed with $4 \%$ paraformaldehyde for $10 \mathrm{~min}$ and stained with Giemsa solution (Merck, Darmstadt, Germany).

Cell cycle analysis. For flow cytometric analysis, adherent and detached cells were harvested and fixed with $70 \%$ ethanol at room temperature for $30 \mathrm{~min}$. After washing with PBS (-), the cells were incubated at $37^{\circ} \mathrm{C}$ for $30 \mathrm{~min}$ with $1 \mathrm{mg} / \mathrm{ml} \mathrm{RNase} \mathrm{I}$ in PBS (-) and stained with $20 \mu \mathrm{g}$ propidium iodide at room temperature for $30 \mathrm{~min}$ in the dark. A total of 10,000 cells were analyzed for DNA content using flow cytometry and CellQuest software (FACSCalibur; BD Biosciences, Franklin Lakes, NJ, USA). Assays were performed in duplicate.

Immunocytochemical staining analysis. HCC1937 and MDA-MB-231 cells were plated onto a 2-well glass slide (Thermo Fisher Scientific, Rochester, NY, USA) at a density of $1.0 \times 10^{4} /$ well and incubated for $24 \mathrm{~h}$ before siRNA transfection. Forty-eight hours post-transfection, the cells were fixed with $4 \%$ paraformaldehyde for $30 \mathrm{~min}$ at $4^{\circ} \mathrm{C}$ and then permeablized with $0.1 \%$ Triton X-100 for $2 \mathrm{~min}$ at room temperature. Subsequently, the cells were covered with $3 \%$ bovine serum albumin for $60 \mathrm{~min}$ at room temperature and then incubated with an anti- $\alpha / \beta$ tubulin antibody (Cell Signaling, Beverly, MA, USA) diluted 1:50 for $1 \mathrm{~h}$. After washing with PBS (-), the cells were stained with an Alexa 488-conjugated antirabbit secondary antibody (Molecular Probes, Eugene, OR, USA) diluted 1:1,000 for $1 \mathrm{~h}$. The nuclei were counterstained with 4',6'-diamidine-2'-phenylindole dihydrochloride (DAPI). Fluorescent images were obtained using an IX71 microscope (Olympus, Tokyo, Japan).

Statistical analysis. Statistical significance was calculated by Mann-Whitney t-test using Stat View 5.0 J software (SAS Institute, Inc., Cary, NC, USA) to compare the gene expression levels between TNBC cells and normal ductal cells, and by Student's two-sided t-test using Microsoft ${ }^{\circledR}$ Excel 2008 to assess cell proliferation, gene expression, and alteration of cell cycle. A difference of $\mathrm{P}<0.05$ was considered statistically significant.

\section{Results}

Identification of genes upregulated or downregulated in TNBCs. To obtain precise expression profiles of TNBC cells, we used LMM to avoid contamination of non-cancer cells, such as adipocytes, fibroblasts, and inflammatory cells from the tissue sections (Fig. 1A, upper panels). Because breast cancer originates from normal breast ductal cells, we used similarly purified populations of normal duct cells as controls (Fig. 1A, lower panels). The precise gene-expression profiles of TNBC by DNA microarray identified 301 genes that were upregulated $>5$-fold in TNBC compared to 13 normal ductal cells, and 321 genes that were downregulated to $<1 / 5$ of the normal ductal cells (Fig. 1B). Table II lists the 301 upregulated genes in TNBC, including ubiquitin-conjugating enzyme E2C (UBE2C)
(14), S100 calcium binding protein P (S100P) (15), ubiquitin carboxyl-terminal esterase L1 (ubiquitin thiolesterase) (UCHL1) (16), pituitary tumor-transforming 1 (PTTG1) (17), ubiquitinconjugating enzyme E2T (UBE2T) (13), ubiquitin-like with PHD and ring finger domains 1 (UHRF1) (18), SIX homeobox 1 (SIXI) (19), and protein regulator of cytokinesis 1 (PRCl) (20), which were previously reported to be overexpressed in breast cancer and involved in mammary carcinogenesis. In particular, topoisomerase (DNA) II $\alpha$ (TOP2A) $(21,22)$, HORMA domain containing 1 (HORMAD1) (23), ATPase family, Fatty acid binding protein 5 (psoriasis-associated) (FABP5) (24), and AAA domain containing 2 (ATAD2) (25) were previously reported to be potentially involved in the carcinogenesis of TNBC, and to serve as prognostic markers or therapeutic targets for TNBC.

On the other hand, Table III lists the 321 genes that were downregulated to $<1 / 5$ of normal ductal cells. Among these significantly downregulated genes, prolactin-induced protein $(P I P)$ and dynein, axonemal, light intermediate chain 1 (DNALI1) were previously shown to be downregulated in TNBC (26). In particular, suppression of WNT inhibitory factor 1 (WIF1) (27) and signal peptide, CUB domain, EGF-like (SCUBE2) (28), both of which function as tumor suppressors, were among the genes that were downregulated as malignancy progressed. These data suggest that silencing or depletion of these genes might lead to the carcinogenesis of TNBC.

Identification of cancer-specific genes. Next, to develop novel therapeutic targets for TNBC with a minimum risk of adverse events, we performed a DNA microarray analysis of normal human vital organs consisting of the heart, lung, liver and kidney as well as TNBC cases and attempted to identify genes whose expression was exclusively upregulated in TNBC, but not expressed in normal vital organs. We identified 104 genes, which were specifically upregulated in TNBC, including cancer-specific molecules such as NIMA-related kinase 2 (NEK2) $(29,30)$, PDZ binding kinase $(P B K)(31)$, denticleless homolog (Drosohila) (DTL) (32), maternal leucine zipper kinase $(M E L K)(33)$, and kinesin family member C (KIF2C) (34), which have previously been shown to be involved in breast carcinogenesis (Fig. 1C and Table IV).

Functional gene annotation clustering analysis. To elucidate the biological processes and pathways characterized in TNBC, we performed a functional analysis of these upregulated or downregulated genes in 30 TNBC cases using the gene annotation clustering of the DAVID algorithm. We identified the most prominent cluster (cluster 1; gene enrichment score, 29.90) composed of various functional annotation terms consisting of 87 upregulated genes in TNBC (Table V). Cluster 1 consisted almost entirely of cell cycle-associated genes as represented by nuclear division (fold enrichment, 15.04), mitosis (fold enrichment, 15.04), $\mathrm{M}$ phase of the mitotic cell cycle (fold enrichment, 14.78), organelle fission (fold enrichment, 14.45), and $\mathrm{M}$ phase (fold enrichment, 12.90) (Fig. 2). These findings suggest that most of the upregulated genes in TNBC might be functionally responsible for cell cycle progression.

On the other hand, we also identified the most prominent cluster functionally deactivated in TNBC based on down- 
Table II. Genes significantly upregulated in TNBC compared with normal ductal cells.

\begin{tabular}{|c|c|c|c|c|c|}
\hline Probe ID & Accession no. & Symbol & Gene name & $\begin{array}{l}\text { Fold change } \\
\qquad(\log )\end{array}$ & P-value \\
\hline A_24_P334130 & NM_054034 & FN1 & Fibronectin 1 & 5.33 & $1.26 \mathrm{E}-04$ \\
\hline A_24_P940678 & N/A & $\mathrm{N} / \mathrm{A}$ & & 5.07 & $1.26 \mathrm{E}-04$ \\
\hline A_23_P367618 & NM_003412 & $Z I C 1$ & $\begin{array}{l}\text { Zic family member } 1 \text { (odd-paired homolog, } \\
\text { Drosophila) }\end{array}$ & 5.01 & $1.26 \mathrm{E}-04$ \\
\hline A_23_P118834 & NM_001067 & TOP $2 A$ & Topoisomerase (DNA) II $\alpha 170$ kDa & 4.76 & $1.26 \mathrm{E}-04$ \\
\hline A_32_P119154 & BE138567 & $\mathrm{N} / \mathrm{A}$ & & 4.75 & $1.26 \mathrm{E}-04$ \\
\hline A_23_P35219 & NM_002497 & NEK2 & NIMA (never in mitosis gene a)-related kinase 2 & 4.67 & $1.26 \mathrm{E}-04$ \\
\hline A_23_P166360 & NM_206956 & $P R A M E$ & Preferentially expressed antigen in melanoma & 4.64 & $1.26 \mathrm{E}-04$ \\
\hline A_24_P332314 & NM_198947 & FAM111B & Family with sequence similarity 111 , member B & 4.63 & $1.26 \mathrm{E}-04$ \\
\hline A_24_P413884 & NM_001809 & CENPA & Centromere protein $\mathrm{A}$ & 4.59 & $1.26 \mathrm{E}-04$ \\
\hline A_23_P68610 & NM_012112 & $T P X 2$ & $\begin{array}{l}\text { TPX2, microtubule-associated, homolog } \\
\text { (Xenopus laevis) }\end{array}$ & 4.58 & $1.26 \mathrm{E}-04$ \\
\hline A_23_P58266 & NM_005980 & $S 100 P$ & S100 calcium binding protein $\mathrm{P}$ & 4.57 & $1.26 \mathrm{E}-04$ \\
\hline A_24_P297539 & NM_181803 & $U B E 2 C$ & Ubiquitin-conjugating enzyme E2C & 4.49 & $1.26 \mathrm{E}-04$ \\
\hline A_23_P401 & NM_016343 & CENPF & Centromere protein F, 350/400 ka (mitosin) & 4.44 & $1.26 \mathrm{E}-04$ \\
\hline A_23_P57379 & NM_003504 & $C D C 45 L$ & CDC45 cell division cycle 45 -like ( $S$. cerevisiae) & 4.44 & $1.26 \mathrm{E}-04$ \\
\hline A_23_P118815 & NM_001012271 & BIRC 5 & Baculoviral IAP repeat-containing 5 & 4.43 & $1.26 \mathrm{E}-04$ \\
\hline A_23_P210853 & NM_021067 & GINS1 & GINS complex subunit 1 (Psf1 homolog) & 4.41 & $1.26 \mathrm{E}-04$ \\
\hline A_23_P258493 & NM_005573 & $L M N B 1$ & Lamin B1 & 4.31 & $1.26 \mathrm{E}-04$ \\
\hline A_24_P119745 & NM_212482 & FN1 & Fibronectin 1 & 4.31 & $1.26 \mathrm{E}-04$ \\
\hline A_24_P680947 & ВC044933 & $K I F 18 B$ & Kinesin family member $18 \mathrm{~B}$ & 4.3 & $1.26 \mathrm{E}-04$ \\
\hline A_32_P92642 & $\mathrm{N} / \mathrm{A}$ & $\mathrm{N} / \mathrm{A}$ & & 4.3 & $1.26 \mathrm{E}-04$ \\
\hline A_23_P356684 & NM_018685 & $A N L N$ & Anillin, actin binding protein & 4.29 & $1.26 \mathrm{E}-04$ \\
\hline A_24_P314571 & BU616832 & N/A & & 4.24 & $1.26 \mathrm{E}-04$ \\
\hline A_23_P98580 & NM_004265 & $F A D S 2$ & Fatty acid desaturase 2 & 4.2 & $1.26 \mathrm{E}-04$ \\
\hline A_23_P52017 & NM_018136 & $A S P M$ & $\begin{array}{l}\text { asp (abnormal spindle) homolog, microcephaly } \\
\text { associated (Drosophila) }\end{array}$ & 4.17 & $1.26 \mathrm{E}-04$ \\
\hline A_24_P20607 & NM_005409 & CXCL11 & Chemokine (C-X-C motif) ligand 11 & 4.16 & 2.33E-04 \\
\hline A_32_P199884 & NM_032132 & HORMAD1 & HORMA domain containing 1 & 4.13 & $2.33 \mathrm{E}-04$ \\
\hline A_23_P70007 & NM_012484 & $H M M R$ & $\begin{array}{l}\text { Hyaluronan-mediated motility receptor } \\
\text { (RHAMM) }\end{array}$ & 4.11 & $1.26 \mathrm{E}-04$ \\
\hline A_23_P22378 & NM_003108 & SOX11 & SRY (sex determining region Y)-box 11 & 4.1 & $1.26 \mathrm{E}-04$ \\
\hline A_23_P259586 & NM_003318 & $T T K$ & TTK protein kinase & 4.09 & $1.26 \mathrm{E}-04$ \\
\hline A_23_P200310 & NM_017779 & $D E P D C 1$ & DEP domain containing 1 & 4.08 & $1.26 \mathrm{E}-04$ \\
\hline A_24_P378331 & NM_170589 & CASC5 & Cancer susceptibility candidate 5 & 4.06 & $1.26 \mathrm{E}-04$ \\
\hline A_23_P111888 & NM_138455 & CTHRC1 & Collagen triple helix repeat containing 1 & 4.05 & $1.26 \mathrm{E}-04$ \\
\hline A_23_P48835 & NM_138555 & KIF23 & Kinesin family member 23 & 4.05 & $1.26 \mathrm{E}-04$ \\
\hline A_23_P115872 & NM_018131 & CEP55 & Centrosomal protein $55 \mathrm{kDa}$ & 4.03 & $1.26 \mathrm{E}-04$ \\
\hline A_23_P132956 & NM_004181 & $U C H L 1$ & $\begin{array}{l}\text { Ubiquitin carboxyl-terminal esterase L1 } \\
\text { (ubiquitin thiolesterase) }\end{array}$ & 4.03 & $1.26 \mathrm{E}-04$ \\
\hline A_24_P911179 & NM_018136 & $A S P M$ & $\begin{array}{l}\text { asp (abnormal spindle) homolog, microcephaly } \\
\text { associated (Drosophila) }\end{array}$ & 4.02 & $1.26 \mathrm{E}-04$ \\
\hline A_23_P408955 & NM_004091 & $E 2 F 2$ & E2F transcription factor 2 & 4.02 & $1.26 \mathrm{E}-04$ \\
\hline A_23_P7636 & NM_004219 & PTTG1 & Pituitary tumor-transforming 1 & 4 & $1.26 \mathrm{E}-04$ \\
\hline A_23_P204941 & NM_004004 & $G J B 2$ & Gap junction protein, $\beta 2,26 \mathrm{kDa}$ & 4 & $1.26 \mathrm{E}-04$ \\
\hline A_23_P18452 & NM_002416 & $C X C L 9$ & Chemokine (C-X-C motif) ligand 9 & 3.94 & 2.33E-04 \\
\hline A_24_P96780 & NM_016343 & CENPF & Centromere protein $\mathrm{F}, 350 / 400 \mathrm{ka}$ (mitosin) & 3.92 & $1.26 \mathrm{E}-04$ \\
\hline A_23_P69537 & NM_006681 & $N M U$ & Neuromedin U & 3.9 & $1.26 \mathrm{E}-04$ \\
\hline
\end{tabular}


Table II. Continued.

\begin{tabular}{|c|c|c|c|c|c|}
\hline Probe ID & Accession no. & Symbol & Gene name & $\begin{array}{l}\text { Fold change } \\
\qquad(\log )\end{array}$ & P-value \\
\hline A_24_P14156 & NM_006101 & NDC80 & $\begin{array}{l}\text { NDC } 80 \text { homolog, kinetochore complex } \\
\text { component }(\text { S. cerevisiae })\end{array}$ & 3.86 & $1.26 \mathrm{E}-04$ \\
\hline A_23_P254733 & NM_024629 & $M L F 1 I P$ & MLF1 interacting protein & 3.85 & $1.26 \mathrm{E}-04$ \\
\hline A_23_P74115 & NM_003579 & $R A D 54 L$ & RAD54-like (S. cerevisiae) & 3.84 & $1.26 \mathrm{E}-04$ \\
\hline A_23_P50108 & NM_006101 & NDC80 & $\begin{array}{l}\text { NDC80 homolog, kinetochore complex } \\
\text { component (S. cerevisiae) }\end{array}$ & 3.84 & $1.26 \mathrm{E}-04$ \\
\hline A_24_P150160 & NM_004265 & $F A D S 2$ & Fatty acid desaturase 2 & 3.83 & $1.26 \mathrm{E}-04$ \\
\hline A_23_P155815 & NM_022346 & $N C A P G$ & Non-SMC condensin I complex, subunit G & 3.82 & $1.26 \mathrm{E}-04$ \\
\hline A_23_P125278 & NM_005409 & CXCL11 & Chemokine (C-X-C motif) ligand 11 & 3.81 & $1.26 \mathrm{E}-04$ \\
\hline A_23_P51085 & NM_020675 & $S P C 25$ & $\begin{array}{l}\text { SPC25, NDC80 kinetochore complex } \\
\text { component, homolog (S. cerevisiae) }\end{array}$ & 3.81 & $1.26 \mathrm{E}-04$ \\
\hline A_23_P133123 & NM_032117 & $M N D 1$ & $\begin{array}{l}\text { Meiotic nuclear divisions } 1 \text { homolog } \\
\text { (S. cerevisiae) }\end{array}$ & 3.8 & $1.26 \mathrm{E}-04$ \\
\hline A_32_P62997 & NM_018492 & $P B K$ & PDZ binding kinase & 3.8 & $1.26 \mathrm{E}-04$ \\
\hline A_23_P256956 & NM_005733 & $K I F 20 A$ & Kinesin family member $20 \mathrm{~A}$ & 3.79 & $1.26 \mathrm{E}-04$ \\
\hline A_24_P933613 & N/A & $\mathrm{N} / \mathrm{A}$ & & 3.78 & $1.26 \mathrm{E}-04$ \\
\hline A_23_P212844 & NM_006342 & TACC3 & $\begin{array}{l}\text { Transforming, acidic coiled-coil containing } \\
\text { protein } 3\end{array}$ & 3.78 & $1.26 \mathrm{E}-04$ \\
\hline A_24_P254705 & NM_020394 & ZNF695 & Zinc finger protein 695 & 3.76 & $1.26 \mathrm{E}-04$ \\
\hline A_23_P115482 & NM_014176 & $U B E 2 T$ & Ubiquitin-conjugating enzyme E2T (putative) & 3.75 & $1.26 \mathrm{E}-04$ \\
\hline A_32_P201723 & N/A & N/A & & 3.73 & $1.26 \mathrm{E}-04$ \\
\hline A_23_P256425 & NM_014479 & $A D A M D E C 1$ & ADAM-like, decysin 1 & 3.73 & $1.26 \mathrm{E}-04$ \\
\hline A_23_P432352 & NM_001017978 & CXorf61 & Chromosome $\mathrm{X}$ open reading frame 61 & 3.73 & $1.26 \mathrm{E}-04$ \\
\hline A_23_P208880 & NM_013282 & $U H R F 1$ & $\begin{array}{l}\text { Ubiquitin-like with PHD and ring finger } \\
\text { domains } 1\end{array}$ & 3.72 & $1.26 \mathrm{E}-04$ \\
\hline A_23_P323751 & NM_030919 & $F A M 83 D$ & Family with sequence similarity 83 , member D & 3.71 & $1.26 \mathrm{E}-04$ \\
\hline A_23_P48669 & NM_005192 & $C D K N 3$ & Cyclin-dependent kinase inhibitor 3 & 3.71 & $1.26 \mathrm{E}-04$ \\
\hline A_24_P234196 & NM_001034 & $R R M 2$ & Ribonucleotide reductase M2 & 3.69 & $1.26 \mathrm{E}-04$ \\
\hline A_23_P253791 & NM_004345 & CAMP & Cathelicidin antimicrobial peptide & 3.69 & $1.26 \mathrm{E}-04$ \\
\hline A_23_P76914 & NM_005982 & SIX1 & SIX homeobox 1 & 3.67 & 4.43E-04 \\
\hline A_23_P94571 & NM_004432 & ELAVL2 & $\begin{array}{l}\text { ELAV (embryonic lethal, abnormal vision, } \\
\text { Drosophila)-like } 2 \text { (Hu antigen } \mathrm{B})\end{array}$ & 3.67 & $1.26 \mathrm{E}-04$ \\
\hline A_23_P200222 & NM_033300 & $L R P 8$ & $\begin{array}{l}\text { Low density lipoprotein receptor-related } \\
\text { protein } 8 \text {, apolipoprotein E receptor }\end{array}$ & 3.67 & $1.26 \mathrm{E}-04$ \\
\hline A_24_P416079 & NM_016359 & NUSAP1 & Nucleolar and spindle associated protein 1 & 3.66 & $1.26 \mathrm{E}-04$ \\
\hline A_23_P104651 & NM_080668 & $C D C A 5$ & Cell division cycle associated 5 & 3.65 & $1.26 \mathrm{E}-04$ \\
\hline A_23_P150667 & NM_031217 & KIF $18 A$ & Kinesin family member $18 \mathrm{~A}$ & 3.64 & $1.26 \mathrm{E}-04$ \\
\hline A_24_P859859 & N/A & N/A & & 3.63 & 4.43E-04 \\
\hline A_23_P312150 & NM_001956 & EDN2 & Endothelin 2 & 3.61 & $1.26 \mathrm{E}-04$ \\
\hline A_23_P375 & NM_018101 & CDCA 8 & Cell division cycle associated 8 & 3.59 & $1.26 \mathrm{E}-04$ \\
\hline A_32_P68525 & ВC035392 & N/A & & 3.58 & $1.26 \mathrm{E}-04$ \\
\hline A_23_P43490 & NM_058197 & $C D K N 2 \mathrm{~A}$ & $\begin{array}{l}\text { Cyclin-dependent kinase inhibitor 2A } \\
\text { (melanoma, p16, inhibits CDK4) }\end{array}$ & 3.56 & $1.26 \mathrm{E}-04$ \\
\hline A_23_P1691 & NM_002421 & $M M P 1$ & $\begin{array}{l}\text { Matrix metallopeptidase } 1 \text { (interstitial } \\
\text { collagenase) }\end{array}$ & 3.55 & $1.26 \mathrm{E}-04$ \\
\hline A_23_P117852 & NM_014736 & KIAA0101 & KIAA0101 & 3.54 & $1.26 \mathrm{E}-04$ \\
\hline A_24_P319613 & NM_002497 & $N E K 2$ & NIMA (never in mitosis gene a)-related kinase 2 & 3.53 & $1.26 \mathrm{E}-04$ \\
\hline A_23_P10385 & NM_016448 & $D T L$ & Denticleless homolog (Drosophila) & 3.53 & $1.26 \mathrm{E}-04$ \\
\hline
\end{tabular}


Table II. Continued.

\begin{tabular}{|c|c|c|c|c|c|}
\hline Probe ID & Accession no. & Symbol & Gene name & $\begin{array}{l}\text { Fold change } \\
\qquad(\log )\end{array}$ & P-value \\
\hline A_32_P1173 & NM_138441 & C6orf150 & Chromosome 6 open reading frame 150 & 3.51 & $1.26 \mathrm{E}-04$ \\
\hline A_23_P94422 & NM_014791 & $M E L K$ & Maternal embryonic leucine zipper kinase & 3.5 & $1.26 \mathrm{E}-04$ \\
\hline A_23_P340909 & ВC013418 & $S K A 3$ & $\begin{array}{l}\text { Spindle and kinetochore associated complex } \\
\text { subunit } 3\end{array}$ & 3.48 & $1.26 \mathrm{E}-04$ \\
\hline A_23_P385861 & NM_152562 & $C D C A 2$ & Cell division cycle associated 2 & 3.47 & $1.26 \mathrm{E}-04$ \\
\hline A_23_P124417 & NM_004336 & $B U B 1$ & $\begin{array}{l}\text { Budding uninhibited by benzimidazoles } 1 \\
\text { homolog (yeast) }\end{array}$ & 3.47 & $1.26 \mathrm{E}-04$ \\
\hline A_24_P257099 & NM_018410 & HJURP & Holliday junction recognition protein & 3.43 & $1.26 \mathrm{E}-04$ \\
\hline A_24_P270460 & NM_005532 & IFI27 & Interferon, $\alpha$-inducible protein 27 & 3.41 & 2.33E-04 \\
\hline A_23_P206059 & NM_003981 & PRCl & Protein regulator of cytokinesis 1 & 3.39 & $1.26 \mathrm{E}-04$ \\
\hline A_23_P74349 & NM_145697 & $N U F 2$ & $\begin{array}{l}\text { NUF2, NDC80 kinetochore complex } \\
\text { component, homolog (S. cerevisiae) }\end{array}$ & 3.36 & $1.26 \mathrm{E}-04$ \\
\hline A_24_P302584 & NM_003108 & SOX11 & SRY (sex determining region Y)-box 11 & 3.36 & 4.43E-04 \\
\hline A_24_P68088 & NR_002947 & TCAM1 & $\begin{array}{l}\text { Testicular cell adhesion molecule } 1 \text { homolog } \\
\text { (mouse) }\end{array}$ & 3.35 & $2.33 \mathrm{E}-04$ \\
\hline A_24_P605612 & NM_003247 & $T H B S 2$ & Thrombospondin 2 & 3.34 & $1.26 \mathrm{E}-04$ \\
\hline A_24_P366033 & NM_018098 & ECT2 & $\begin{array}{l}\text { Epithelial cell transforming sequence } 2 \\
\text { oncogene }\end{array}$ & 3.34 & $1.26 \mathrm{E}-04$ \\
\hline A_23_P93258 & NM_003537 & HIST1H3B & Histone cluster $1, \mathrm{H} 3 \mathrm{~b}$ & 3.33 & $1.26 \mathrm{E}-04$ \\
\hline A_23_P211762 & $\mathrm{N} / \mathrm{A}$ & COL8A1 & Collagen, type VIII, $\alpha 1$ & 3.29 & 4.43E-04 \\
\hline A_23_P77493 & NM_006086 & $T U B B 3$ & Tubulin, $\beta 3$ & 3.29 & $1.26 \mathrm{E}-04$ \\
\hline A_23_P204947 & NM_004004 & $G J B 2$ & Gap junction protein, $\beta 2,26 \mathrm{kDa}$ & 3.29 & $1.26 \mathrm{E}-04$ \\
\hline A_23_P149668 & NM_014875 & KIF 14 & Kinesin family member 14 & 3.29 & $1.26 \mathrm{E}-04$ \\
\hline A_23_P34325 & NM_033300 & $L R P 8$ & $\begin{array}{l}\text { Low density lipoprotein receptor-related } \\
\text { protein } 8 \text {, apolipoprotein E receptor }\end{array}$ & 3.28 & $1.26 \mathrm{E}-04$ \\
\hline A_32_P56154 & N/A & N/A & & 3.28 & $1.26 \mathrm{E}-04$ \\
\hline A_32_P10403 & BU618641 & SERPINE1 & $\begin{array}{l}\text { Serpin peptidase inhibitor, clade } E \text { (nexin, } \\
\text { plasminogen activator inhibitor type } 1) \text {, } \\
\text { member } 1\end{array}$ & 3.27 & $1.26 \mathrm{E}-04$ \\
\hline A_23_P138507 & NM_001786 & $C D C 2$ & Cell division cycle $2, \mathrm{G} 1 \rightarrow \mathrm{S}$ and $\mathrm{G} 2 \rightarrow \mathrm{M}$ & 3.24 & $1.26 \mathrm{E}-04$ \\
\hline A_23_P48513 & NM_005532 & IFI27 & Interferon, $\alpha$-inducible protein 27 & 3.23 & $1.26 \mathrm{E}-04$ \\
\hline A_23_P49972 & NM_001254 & CDC6 & Cell division cycle 6 homolog (S. cerevisiae) & 3.22 & $1.26 \mathrm{E}-04$ \\
\hline A_24_P306896 & XR_040656 & LOC283711 & Hypothetical protein LOC283711 & 3.22 & $1.26 \mathrm{E}-04$ \\
\hline A_23_P44684 & NM_018098 & ECT2 & $\begin{array}{l}\text { Epithelial cell transforming sequence } 2 \\
\text { oncogene }\end{array}$ & 3.21 & $1.26 \mathrm{E}-04$ \\
\hline A_24_P161773 & N/A & N/A & & 3.2 & $1.26 \mathrm{E}-04$ \\
\hline A_23_P100344 & NM_014321 & ORC6L & Origin recognition complex, subunit 6 like (yeast) & 3.2 & $1.26 \mathrm{E}-04$ \\
\hline A_32_P162183 & NM_000063 & $C 2$ & Complement component 2 & 3.18 & $1.26 \mathrm{E}-04$ \\
\hline A_23_P163481 & NM_001211 & $B U B 1 B$ & $\begin{array}{l}\text { Budding uninhibited by benzimidazoles } 1 \\
\text { homolog } \beta \text { (yeast) }\end{array}$ & 3.17 & $1.26 \mathrm{E}-04$ \\
\hline A_32_P113784 & $\mathrm{N} / \mathrm{A}$ & N/A & & 3.16 & $1.26 \mathrm{E}-04$ \\
\hline A_32_P87849 & N/A & N/A & & 3.16 & $1.26 \mathrm{E}-04$ \\
\hline A_24_P397107 & NM_001789 & $C D C 25 A$ & Cell division cycle 25 homolog A (S. pombe) & 3.15 & $1.26 \mathrm{E}-04$ \\
\hline A_23_P209200 & NM_001238 & CCNE1 & Cyclin E1 & 3.15 & $1.26 \mathrm{E}-04$ \\
\hline A_32_P16625 & $\mathrm{N} / \mathrm{A}$ & $\mathrm{N} / \mathrm{A}$ & & 3.15 & $1.26 \mathrm{E}-04$ \\
\hline A_23_P58321 & NM_001237 & CCNA2 & Cyclin A2 & 3.15 & $1.26 \mathrm{E}-04$ \\
\hline A_24_P37903 & $\mathrm{N} / \mathrm{A}$ & $L O X$ & Lysyl oxidase & 3.12 & $1.26 \mathrm{E}-04$ \\
\hline
\end{tabular}


Table II. Continued.

Probe ID Accession no. Symbol Gene name

Fold change P-value $(\log )$

A_32_P64919 NM_001042517 DIAPH3 Diaphanous homolog 3 (Drosophila)

3.12

$1.26 \mathrm{E}-04$

A_23_P379614 NM_007280

OIP5

A_23_P206441 NM_000135

FANCA

Opa interacting protein 5

3.12

$1.26 \mathrm{E}-04$

A_23_P16915 NM_012413

$Q P C T$

Fanconi anemia, complementation group A

3.09

$1.26 \mathrm{E}-04$

A_23_P137173 NM_021992

TMSB15A

Glutaminyl-peptide cyclotransferase

3.09

$1.26 \mathrm{E}-04$

A_24_P313504 NM_005030

PLK1

Thymosin $\beta$ 15a

3.07

$1.26 \mathrm{E}-04$

A_23_P251421 NM_031942

CDCA7

Polo-like kinase 1 (Drosophila)

A_23_P252292 NM_006733

CENPI

Cell division cycle associated 7

3.07

$1.26 \mathrm{E}-04$

3.06

$1.26 \mathrm{E}-04$

A_23_P158725 NM_001042422 SLC16A3

Centromere protein I

3.04

$1.26 \mathrm{E}-04$

Solute carrier family 16 , member 3

$1.26 \mathrm{E}-04$

A_23_P57417 NM_005940

MMP11 Matrix metallopeptidase11 (stromelysin 3)

A_24_P291044 N/A

A_23_P343927 NM_175065

N/A

A_23_P63789 NM_032997

$H I S T 2 H 2 A B$ Histone cluster 2, H2ab

3.04

3.03

1.26E-04

ZWINT

3.02

$1.26 \mathrm{E}-04$

A_23_P123596 NM_000170

GLDC

A_23_P88731 NM_002875

RAD51

\section{A_23_P161474 NM_182751}

MCM10

\section{A_24_P303354 NM_021064}

HIST1H2AG Histone cluster 1, H2ag

A_23_P10518 NM_016521

TFDP3

A_24_P247660 NM_001002033

HN1

A_23_P134910 NM_003878

$G G H$

$\begin{array}{ll}\text { A_32_P7193 } & \text { N/A } \\ \text { A_23_P49878 } & \text { NM_019013 } \\ \text { A_24_P359231 } & \text { BC014312 } \\ \text { A_32_P140262 } & \text { N/A } \\ \text { A_23_P55270 } & \text { NM_002988 }\end{array}$

$\mathrm{N} / \mathrm{A}$

FAM64A Family with sequence similarity 64, member A

HIST1H2BJ Histone cluster $1, \mathrm{H} 2 \mathrm{bj}$

$\mathrm{N} / \mathrm{A}$

A_24_P462899 NM_001012507 C6orf173

A_23_P502520 NM_172374

A_23_P253762 N/A

A_23_P214908 AY374131

A_24_P225534 NM_017821

A_23_P203419 NM_013402

A_23_P150935 NM_005480

A_24_P412088 NM_182751

A_23_P71727 NM_001827

A_23_P217236 NM_005342

A_32_P109296 NM_152259

A_23_P89509 NM_006461

A_24_P563068 N/A

A_23_P416468 NM_025049

A_24_P38895 NM_002105

A_23_P52278 NM_004523

A_24_P144543 N/A
CCL18

ILAII

N/A

$\mathrm{N} / \mathrm{A}$

RHBDL2

FADS1

TROAP

MCM10

CKS2

HMGB3

C15orf42

Chemokine (C-C motif) ligand 18 (pulmonary and activation-regulated)

Chromosome 6 open reading frame 173

Interleukin 4 induced 1

2.94

2.94

2.94

2.94

2.94

2.94

2.94

2.94

Minichromosome maintenance complex

component 10

CDC28 protein kinase regulatory subunit 2

2.93

2.92

2.91

2.91

2.91

N/A

PIF 1

$H 2 A F X$

KIF 11

$\mathrm{N} / \mathrm{A}$

Chromosome 15 open reading frame 42

PIF1 5'-to-3' DNA helicase homolog (S. cerevisiae)

2.91

$\mathrm{H} 2 \mathrm{~A}$ histone family, member $\mathrm{X}$

Kinesin family member 11
ZW10 interactor

Glycine dehydrogenase (decarboxylating)

RAD51 homolog (RecA homolog, E. coli)

(S. cerevisiae)

Minichromosome maintenance complex component 10

Transcription factor Dp family, member 3

Hematological and neurological expressed 1

$\gamma$-glutamyl hydrolase (conjugase,

folylpolygammaglutamyl hydrolase)

$1.26 \mathrm{E}-04$

$1.26 \mathrm{E}-04$

$1.26 \mathrm{E}-04$

$1.26 \mathrm{E}-04$

1.26E-04

$1.26 \mathrm{E}-04$

$1.26 \mathrm{E}-04$

$1.26 \mathrm{E}-04$

$1.26 \mathrm{E}-04$

$1.26 \mathrm{E}-04$

$1.26 \mathrm{E}-04$

$1.26 \mathrm{E}-04$

$1.26 \mathrm{E}-04$

$1.26 \mathrm{E}-04$

$1.26 \mathrm{E}-04$

$1.26 \mathrm{E}-04$

$1.26 \mathrm{E}-04$

1.26E-04

$1.26 \mathrm{E}-04$

1.26E-04

$1.26 \mathrm{E}-04$

$1.26 \mathrm{E}-04$

1.26E-04

$1.26 \mathrm{E}-04$

$1.26 \mathrm{E}-04$

$1.26 \mathrm{E}-04$

$1.26 \mathrm{E}-04$

$1.26 \mathrm{E}-04$

$1.26 \mathrm{E}-04$ 
Table II. Continued.

Probe ID Accession no. Symbol Gene name $\quad$ Fold change P-value

\begin{tabular}{|c|c|c|c|c|c|}
\hline A_24_P71468 & NM_012413 & $Q P C T$ & Glutaminyl-peptide cyclotransferase & 2.88 & $2.33 \mathrm{E}-04$ \\
\hline A_23_P116123 & NM_001274 & CHEK1 & CHK1 checkpoint homolog (S. pombe) & 2.88 & $1.26 \mathrm{E}-04$ \\
\hline A_32_P106235 & N/A & N/A & & 2.87 & $1.26 \mathrm{E}-04$ \\
\hline A_24_P139152 & AL359062 & COL8A1 & Collagen, type VIII, $\alpha 1$ & 2.87 & 4.43E-04 \\
\hline A_23_P36831 & NM_003979 & GPRC5A & $\begin{array}{l}\text { G protein-coupled receptor, family } \mathrm{C} \text {, group } 5 \text {, } \\
\text { member A }\end{array}$ & 2.87 & $1.26 \mathrm{E}-04$ \\
\hline A_23_P387471 & NM_005931 & $M I C B$ & MHC class I polypeptide-related sequence B & 2.85 & $1.26 \mathrm{E}-04$ \\
\hline A_23_P9574 & NM_018098 & ECT2 & Epithelial cell transforming sequence 2 oncogene & 2.84 & $1.26 \mathrm{E}-04$ \\
\hline A_24_P535256 & AK001903 & INHBA & Inhibin, $\beta A$ & 2.84 & $1.26 \mathrm{E}-04$ \\
\hline A_24_P76521 & AK056691 & $G S G 2$ & germ cell associated 2 (haspin) & 2.83 & $1.26 \mathrm{E}-04$ \\
\hline A_23_P103795 & NM_138959 & VANGL1 & vang-like 1 (van gogh, Drosophila) & 2.83 & $1.26 \mathrm{E}-04$ \\
\hline A_32_P74409 & NM_001145033 & LOC387763 & Hypothetical protein LOC387763 & 2.83 & $1.26 \mathrm{E}-04$ \\
\hline A_23_P100632 & NM_001002033 & $H N 1$ & Hematological and neurological expressed 1 & 2.83 & $1.26 \mathrm{E}-04$ \\
\hline A_23_P126212 & NM_022111 & $C L S P N$ & Claspin homolog (Xenopus laevis) & 2.83 & $1.26 \mathrm{E}-04$ \\
\hline A_24_P659113 & NM_152523 & CCNYL1 & Cyclin Y-like 1 & 2.83 & $1.26 \mathrm{E}-04$ \\
\hline A_24_P367227 & NM_001144755 & $M Y B L 1$ & $\begin{array}{l}\mathrm{v} \text {-myb myeloblastosis viral oncogene homolog } \\
\text { (avian)-like } 1\end{array}$ & 2.82 & $1.26 \mathrm{E}-04$ \\
\hline A_23_P162719 & NM_030932 & DIAPH3 & Diaphanous homolog 3 (Drosophila) & 2.81 & $1.26 \mathrm{E}-04$ \\
\hline A_32_P221799 & NM_003514 & HISTIH2AM & Histone cluster 1, H2am & 2.81 & $1.26 \mathrm{E}-04$ \\
\hline A_23_P60120 & NM_031415 & GSDMC & Gasdermin $\mathrm{C}$ & 2.81 & 2.33E-04 \\
\hline A_24_P902509 & NM_018193 & FANCI & Fanconi anemia, complementation group I & 2.8 & $1.26 \mathrm{E}-04$ \\
\hline A_23_P50096 & NM_001071 & TYMS & Thymidylate synthetase & 2.79 & $1.26 \mathrm{E}-04$ \\
\hline A_32_P143245 & NM_001012507 & C6orf173 & Chromosome 6 open reading frame 173 & 2.79 & $1.26 \mathrm{E}-04$ \\
\hline A_23_P155969 & NM_014264 & PLK4 & Polo-like kinase 4 (Drosophila) & 2.79 & $1.26 \mathrm{E}-04$ \\
\hline A_23_P62021 & N/A & N/A & & 2.78 & $1.26 \mathrm{E}-04$ \\
\hline A_32_P183218 & NM_153695 & ZNF367 & Zinc finger protein 367 & 2.77 & $1.26 \mathrm{E}-04$ \\
\hline A_23_P46118 & NM_001821 & CHML & Choroideremia-like (Rab escort protein 2) & 2.76 & 2.33E-04 \\
\hline A_23_P327643 & N/A & N/A & & 2.75 & $1.26 \mathrm{E}-04$ \\
\hline A_23_P375104 & NM_018193 & FANCI & Fanconi anemia, complementation group I & 2.75 & $1.26 \mathrm{E}-04$ \\
\hline A_23_P1823 & NM_000280 & РАХ6 & Paired box 6 & 2.75 & $1.26 \mathrm{E}-04$ \\
\hline A_23_P168014 & NM_021066 & HISTIH2AJ & Histone cluster 1, H2aj & 2.74 & $1.26 \mathrm{E}-04$ \\
\hline A_24_P413126 & NM_020182 & PMEPAl & $\begin{array}{l}\text { Prostate transmembrane protein, androgen } \\
\text { induced } 1\end{array}$ & 2.74 & $1.26 \mathrm{E}-04$ \\
\hline A_23_P80032 & NM_005225 & $E 2 F 1$ & $\mathrm{E} 2 \mathrm{~F}$ transcription factor 1 & 2.74 & $1.26 \mathrm{E}-04$ \\
\hline A_23_P215976 & NM_057749 & CCNE2 & Cyclin E2 & 2.72 & 2.33E-04 \\
\hline A_32_P231415 & AF132203 & $S C D$ & Stearoyl-CoA desaturase ( $\delta$-9-desaturase) & 2.72 & $1.26 \mathrm{E}-04$ \\
\hline A_23_P370989 & NM_005914 & MCM4 & $\begin{array}{l}\text { Minichromosome maintenance complex } \\
\text { component } 4\end{array}$ & 2.72 & $1.26 \mathrm{E}-04$ \\
\hline A_23_P216429 & NM_017680 & $A S P N$ & Asporin & 2.71 & $1.26 \mathrm{E}-04$ \\
\hline A_24_P195621 & NR_027288 & LOC341056 & SUMO-1 activating enzyme subunit 1 pseudogene & 2.71 & $1.26 \mathrm{E}-04$ \\
\hline A_32_P151800 & NM_207418 & FAM72D & Family with sequence similarity 72, member D & 2.7 & $1.26 \mathrm{E}-04$ \\
\hline A_23_P122197 & NM_031966 & CCNB1 & Cyclin B1 & 2.7 & $1.26 \mathrm{E}-04$ \\
\hline A_23_P34788 & NM_006845 & $\mathrm{KIF} 2 \mathrm{C}$ & Kinesin family member $2 \mathrm{C}$ & 2.7 & $1.26 \mathrm{E}-04$ \\
\hline A_32_P206698 & NM_001826 & $C K S 1 B$ & $\mathrm{CDC} 28$ protein kinase regulatory subunit $1 \mathrm{~B}$ & 2.7 & $1.26 \mathrm{E}-04$ \\
\hline A_23_P99292 & NM_006479 & $R A D 51 A P 1$ & RAD51 associated protein 1 & 2.7 & $1.26 \mathrm{E}-04$ \\
\hline A_23_P133956 & NM_002263 & KIFCl & Kinesin family member $\mathrm{C} 1$ & 2.69 & $1.26 \mathrm{E}-04$ \\
\hline A_32_P143496 & N/A & N/A & & 2.69 & $1.26 \mathrm{E}-04$ \\
\hline A_32_P163858 & NM_005063 & $S C D$ & Stearoyl-CoA desaturase ( $\delta$-9-desaturase) & 2.69 & $1.26 \mathrm{E}-04$ \\
\hline
\end{tabular}


Table II. Continued.

Probe ID Accession no. Symbol Gene nam

Fold change P-value $(\log )$

A_32_P175557 R01145 N/A

A_23_P63618

NM_005063

$\mathrm{N} / \mathrm{A}$

$S C D$

A_23_P88630 NM_000057

$B L M$

A_24_P276102 NM_183404

RBLI

A_23_P135385 N/A

N/A

A_23_P57658

NM_020386

HRASLS

A_23_P23303

NM_003686

EXO1

A_23_P88691

NM_000745

CHRNA5

NR_002219

EPRI

A_23_P24444

NM_001360

DHCR7

A_23_P43157

NM_001080416

$M Y B L 1$

A_23_P88740 NM_018455

CENPN

A_23_P131866 NM_198433

AURKA

A_23_P259641

NM_004456

EZH2

A_32_P72341 NM_173084

TRIM59

A_24_P227091 NM_004523

A_23_P145238 NM_080593

A_23_P136805 NM_014783

A_23_P167997 NM_003518

A_23_P63402 NM_013296

A_24_P192994 NM_013402

A_23_P25559 NM_005845

KIF 11

HIST1H2BK

ARHGAP11A

HIST1H2BG

GPSM2

Stearoyl-CoA desaturase ( $\delta$-9-desaturase)

2.69

1.26E-04

2.69

$1.26 \mathrm{E}-04$

2.68

$1.26 \mathrm{E}-04$

2.68

$1.26 \mathrm{E}-04$

Retinoblastoma-like 1 (p107)

2.68

$1.26 \mathrm{E}-04$

2.67

$1.26 \mathrm{E}-04$

2.67

$1.26 \mathrm{E}-04$

Exonuclease 1

2.67

$1.26 \mathrm{E}-04$

2.66

$1.26 \mathrm{E}-04$ coding)

7-dehydrocholesterol reductase

2.65

$1.26 \mathrm{E}-04$

v-myb myeloblastosis viral oncogene homolog

(avian)-like 1

$2.65 \quad 2.33 \mathrm{E}-04$

2.64

$1.26 \mathrm{E}-04$

entromere protein $\mathrm{N}$

2.64

$1.26 \mathrm{E}-04$

Enhancer of zeste homolog 2 (Drosophila)

2.64

$1.26 \mathrm{E}-04$

2.62

2.61

$1.26 \mathrm{E}-04$

Kinesin family member 11

2.61

$1.26 \mathrm{E}-04$

Histone cluster $1, \mathrm{H} 2 \mathrm{bk}$

2.6

$1.26 \mathrm{E}-04$

Rho GTPase activating protein $11 \mathrm{~A}$

2.6

$1.26 \mathrm{E}-04$

Histone cluster $1, \mathrm{H} 2 \mathrm{bg}$

G-protein signaling modulator 2 (AGS3-like,

C. elegans)

FADS1 Fatty acid desaturase 1

ABCC4

ATP-binding cassette, sub-family C

(CFTR/MRP), member 4

A_23_P309381 NM_001040874 HIST2H2AA4 Histone cluster 2, H2aa4

A_23_P35871 NM_024680 E2F8 $\quad$ E2F transcription factor 8

A_23_P207307 N/A N/A

A_24_P399888 NM_001002876 CENPM

Centromere protein $\mathrm{M}$

$1.26 \mathrm{E}-04$

2.6

$1.26 \mathrm{E}-04$

2.59

1.26E-04

2.59

3.41E-04

$1.26 \mathrm{E}-04$

2.58

$1.26 \mathrm{E}-04$

2.58

$1.26 \mathrm{E}-04$

2.58

2.57

$1.26 \mathrm{E}-04$

ADAM metallopeptidase with thrombospondin

3.41E-04

A_23_P21706 NM_001905

CTPS

type 1 motif, 4

A_24_P174924 NM_003537

HIST1H3B

CTP synthase

2.57

$1.26 \mathrm{E}-04$

A_23_P155989 NM_022145

CENPK

Histone cluster $1, \mathrm{H} 3 \mathrm{~b}$

A_23_P103981 NM_001040874

HIST2H $2 A A 4$

Centromere protein $\mathrm{K}$

2.57

$1.26 \mathrm{E}-04$

2.57

$1.26 \mathrm{E}-04$

NM_006516

SLC2AI

Solute carrier family 2 (facilitated glucose

2.56

$1.26 \mathrm{E}-04$

2.56

$1.26 \mathrm{E}-04$

transporter), member 1

A_23_P420551 NM_007174

CIT

Citron (rho-interacting, serine/threonine kinase 21)

2.56

$1.26 \mathrm{E}-04$

SGOL2

Shugoshin-like 2 (S. pombe)

2.54

$1.26 \mathrm{E}-04$

ARHGAP11A Rho GTPase activating protein 11A

2.54

$1.26 \mathrm{E}-04$

A 23 P70448

NM 005325

A_23_P43484

NM_058197

HIST1H1A

Hstone cluster 1, H1a

2.53

$1.26 \mathrm{E}-04$

CDKN2A

Cyclin-dependent kinase inhibitor 2A

$1.26 \mathrm{E}-04$

(melanoma, p16, inhibits CDK4)

A_24_P85539 NM_212482 FNI

A_32_P28704 N/A

$\mathrm{N} / \mathrm{A}$

Fibronectin 1

Thymidine kinase 1 , soluble

2.52

$1.26 \mathrm{E}-04$

A_23_P502425 NM_020409

Mitochondrial ribosomal protein L47
$2.51 \quad 1.26 \mathrm{E}-04$

$2.5 \quad 1.26 \mathrm{E}-04$ 
Table II. Continued.

Probe ID Accession no. Symbol Gene nam

Fold change P-value $(\log )$

A_24_P351466 NM_020890

A_23_P211910 NM_182943

KIAA1524

KIAA1524

2.5

$1.26 \mathrm{E}-04$

PLOD2

Procollagen-lysine, 2-oxoglutarate 5-

2.5

$1.26 \mathrm{E}-04$

A_24_P9321 NM_003533

HIST1H3I Histone cluster 1, H3i

2.49

$1.26 \mathrm{E}-04$

A_24_P334248 NM_014996

PLCHI

Phospholipase C, eta 1

A_24_P819890 NM_001005210

LRRC55

Leucine rich repeat containing 55

2.48

$1.26 \mathrm{E}-04$

A_23_P146456 NM_001333

CTSL2

A_24_P242440 NM_003780

B4GALT2

Cathepsin L2

2.48

2.48

4.43E-04

UDP-Gal: $\beta$ GlcNAc $\beta$ 1,4-galactosyltransferase, polypeptide 2

A_23_P88331 NM_014750 DLGAP5

Discs, large (Drosophila) homolog-associated

2.47

2.33E-04

$1.26 \mathrm{E}-04$

$1.26 \mathrm{E}-04$

A_23_P216068 NM_014109

ATAD2 protein 5

A_32_P31021 N/A

N/A

A_23_P373119 NR_002165

$H M G B 3 L 1$

ATPase family, AAA domain containing 2

2.46

$1.26 \mathrm{E}-04$

2.46

$1.26 \mathrm{E}-04$

A_23_P361419 NM_018369

DEPDC1B

High-mobility group box 3-like 1

2.46

$1.26 \mathrm{E}-04$

DOLK

DEP domain containing $1 \mathrm{~B}$

A_23_P10870 NM_014908

A_23_P420692 NM_015053

PPFIA4

A_23_P146284 NM_003129

SQLE

A_32_P159254 AK123584

$\mathrm{N} / \mathrm{A}$

A_23_P25626 NM_024808

C13orf34

Dolichol kinase

2.45

$1.26 \mathrm{E}-04$

2.44

$1.26 \mathrm{E}-04$

2.43

$1.26 \mathrm{E}-04$

f polypeptide (PTPRF), interacting protein

(liprin), $\alpha 4$

A_23_P59005 NM_000593 TAPI

Squalene epoxidase

2.43

1.26E-04

2.43

2.33E-04

2.43

$1.26 \mathrm{E}-04$

Transporter 1, ATP-binding cassette, sub-family B

2.43

2.33E-04

A_24_P49747 XM_929965

LOC646993 Similar to high mobility group box 3

2.43

$1.26 \mathrm{E}-04$

DSCCl

Defective in sister chromatid cohesion 1

2.42

$1.26 \mathrm{E}-04$

homolog (S. cerevisiae)

A_23_P397341 NM_152341

PAQR4 Progestin and adipoQ receptor family member IV

2.42

$1.26 \mathrm{E}-04$

HIST1H2AE Histone cluster 1, H2ae

2.42

$1.26 \mathrm{E}-04$

GPR137C

$\mathrm{G}$ protein-coupled receptor $137 \mathrm{C}$

2.42

2.41

$1.26 \mathrm{E}-04$

COLIAI

Collagen, type I, $\alpha 1$

A_24_P920968 NM_182625

GEN1

Gen homolog 1, endonuclease (Drosophila)

A_23_P366216 NM_003524

HIST1H2BH

Histone cluster 1, $\mathrm{H} 2 \mathrm{bh}$

A_23_P217049 NM_014286

FREQ

A_32_P194264 NM_001008708

CHAC2

Frequenin homolog (Drosophila)

ChaC, cation transport regulator homolog 2

(E. coli)

A_32_P35839 N/A

N/A

A_23_P154894 NM_000100

A_24_P340066 NM_001421

A_24_P857404 NM_001093725

A_24_P133488 NM_017955

A_23_P339240 NM_014996

A_23_P52410 NM_145307

A_23_P59877

NM_001444

A_23_P29594 NM_052969

A_23_P11984 NM_201649
CSTB

ELF4

MEX3A

CDCA4

PLCHI

RTKN2

FABP5

RPL39L

SLC6A9

Cystatin B (stefin B)

E74-like factor 4 (ets domain transcription factor)

mex-3 homolog A (C. elegans)

Cell division cycle associated 4

Phospholipase C, eta 1

Rhotekin 2

Fatty acid binding protein 5 (psoriasis-associated)

Ribosomal protein L39-like

Solute carrier family 6 (neurotransmitter

transporter, glycine), member 9

STMN1

Stathmin 1
$1.26 \mathrm{E}-04$

$1.26 \mathrm{E}-04$

$1.26 \mathrm{E}-04$

2.41

2.33E-04

2.4

2.33E-04

$1.26 \mathrm{E}-04$

$1.26 \mathrm{E}-04$

$1.26 \mathrm{E}-04$

$1.26 \mathrm{E}-04$

$1.26 \mathrm{E}-04$

2.4

2.39

2.33E-04

2.39

$1.26 \mathrm{E}-04$

2.39

$1.26 \mathrm{E}-04$

2.38

$1.26 \mathrm{E}-04$

A_23_P200866 NM_203401 
Table II. Continued.

\begin{tabular}{|c|c|c|c|c|c|}
\hline Probe ID & Accession no. & Symbol & Gene name & $\begin{array}{l}\text { Fold change } \\
\qquad(\log )\end{array}$ & P-value \\
\hline A_32_P182135 & $\mathrm{N} / \mathrm{A}$ & $\mathrm{N} / \mathrm{A}$ & & 2.36 & $1.26 \mathrm{E}-04$ \\
\hline A_24_P323598 & NM_001017420 & ESCO2 & $\begin{array}{l}\text { Establishment of cohesion } 1 \text { homolog } 2 \\
\text { (S. cerevisiae) }\end{array}$ & 2.36 & $1.26 \mathrm{E}-04$ \\
\hline A_23_P39574 & NM_001080539 & $C C D C 150$ & Coiled-coil domain containing 150 & 2.36 & $1.26 \mathrm{E}-04$ \\
\hline A_24_P275386 & AK025766 & BRI3BP & BRI3 binding protein & 2.36 & $1.26 \mathrm{E}-04$ \\
\hline A_23_P85460 & NM_078626 & $C D K N 2 \mathrm{C}$ & $\begin{array}{l}\text { Cyclin-dependent kinase inhibitor 2C (p18, } \\
\text { inhibits CDK4) }\end{array}$ & 2.35 & $1.26 \mathrm{E}-04$ \\
\hline A_23_P57306 & NM_005441 & CHAF $1 B$ & Chromatin assembly factor 1 , subunit B (p60) & 2.35 & $1.26 \mathrm{E}-04$ \\
\hline A_23_P335329 & NM_004485 & GNG4 & $\begin{array}{l}\text { Guanine nucleotide binding protein } \\
\text { (G protein), } \gamma 4\end{array}$ & 2.35 & $2.33 \mathrm{E}-04$ \\
\hline A_23_P92441 & NM_002358 & $M A D 2 L 1$ & MAD2 mitotic arrest deficient-like 1 (yeast) & 2.35 & $1.26 \mathrm{E}-04$ \\
\hline A_24_P13390 & NM_032814 & RNFT2 & Ring finger protein, transmembrane 2 & 2.35 & $1.26 \mathrm{E}-04$ \\
\hline A_23_P362046 & NM_138779 & C13orf27 & Chromosome 13 open reading frame 27 & 2.34 & $1.26 \mathrm{E}-04$ \\
\hline A_23_P24716 & NM_017870 & TMEM132A & Transmembrane protein $132 \mathrm{~A}$ & 2.34 & $1.26 \mathrm{E}-04$ \\
\hline A_23_P91900 & NM_005496 & SMC4 & structural maintenance of chromosomes 4 & 2.33 & $1.26 \mathrm{E}-04$ \\
\hline A_24_P105102 & NM_182687 & PKMYT1 & $\begin{array}{l}\text { Protein kinase, membrane associated tyrosine/ } \\
\text { threonine } 1\end{array}$ & 2.33 & $1.26 \mathrm{E}-04$ \\
\hline A_24_P244420 & NM_018367 & ACER3 & alkaline ceramidase 3 & 2.33 & 2.33E-04 \\
\hline A_23_P112673 & NM_017975 & ZWILCH & $\begin{array}{l}\text { Zwilch, kinetochore associated, homolog } \\
\text { (Drosophila) }\end{array}$ & 2.33 & $1.26 \mathrm{E}-04$ \\
\hline A_23_P87769 & NM_017915 & C12orf48 & Chromosome 12 open reading frame 48 & 2.33 & $1.26 \mathrm{E}-04$ \\
\hline A_24_P296254 & NM_014783 & ARHGAPIIA & Rho GTPase activating protein 11A & 2.32 & $1.26 \mathrm{E}-04$ \\
\hline A_23_P166306 & NM_000071 & $C B S$ & Cystathionine- $\beta$-synthase & 2.32 & $1.26 \mathrm{E}-04$ \\
\hline
\end{tabular}

N/A, not annotated; P-value, Benjamini-Hochberg false discovery rate of random permutation test; log fold change, between groups. Gene symbol, accession number and gene name were exported from GeneSpring (from the NCBI databases).

regulated genes in TNBC (cluster 2; enrichment score, 6.43). As shown in Table V and Fig. 2, cluster 2 consisted of functions induced by extracellular matrix-cell adhesion-associated genes such as latent transforming growth factor $\beta$ binding protein 2 (LTBP2), laminin $\alpha 3$ (LAMA3) and cell adhesion molecule with homology to L1CAM (close homolog of L1) (CHL1), which have been reported to be downregulated in various tumors (35-37). These results suggest that loss of cell-cell or matrix-cell interactions might be a key mechanism in TNBC progression.

Identification of ASPM and CENPK as novel molecular targets for TNBC therapy. Because the upregulated genes were mainly included in the cell cycle-associated gene cluster as described above, we directed our focus to two cancer-specific genes that function as cell cycle regulators, asp (abnormal spindle) homolog, microcephaly associated (Drosophila) (ASPM), which is fundamental for cytokinesis (38) and centromere protein $\mathrm{K}(C E N P K)$, which is essential for proper kinetochore assembly during mitosis (39), as novel therapeutic targets for TNBC. qRT-PCR experiments confirmed that $A S P M$ and $C E N P K$ genes were significantly upregulated in 48 clinical TNBC cases (Fig. 3A) and five cell lines derived from TNBC (Fig. 3B), but undetectably expressed in a mixture of 13 microdissected normal mammary ductal cells and the normal mammary epithelial cell line MCF10A as well as normal human vital organs.

To ascertain the possible roles of ASPM and CENPK in TNBC cell growth, we knocked down the expression of endogenous ASPM and CENPK in three TNBC cell lines, HCC1937, BT-20 and MDA-MB-231 cells, which highly express both of these genes (Fig. 3), using RNAi. qRT-PCR experiments showed that $A S P M$ and $C E N P K$ were significantly knocked down in cells transfected with siASPM and siCENPK, but not with siEGFP as a control (Fig. 4A). In concordance with their knockdown, the MTT assay clearly revealed growth suppression of breast cancer cells in a time-dependent manner by si $A S P M$ and siCENPK, compared with a control si $E G F P$, which showed no knockdown (Fig. 4B). In addition, a colony formation assay also confirmed that introducing both shRNA-ASPM and $-C E N P K$ constructs remarkably suppressed the growth of BT-20 and MDA-MB-231 cells, respectively, compared with shEGFP-transfected cells (Fig. 4C), suggesting that both genes are likely indispensable for breast cancer cell growth. Furthermore, we investigated the phenotypic alterations of TNBC cells transfected with ASPM and CENPK siRNAs 
Table III. Significantly downregulated genes in TNBC compared with normal ductal cells.

\begin{tabular}{|c|c|c|c|c|c|}
\hline Probe ID & Accession no. & Symbol & Gene name & $\begin{array}{l}\text { Fold change } \\
\qquad(\log )\end{array}$ & P-value \\
\hline A_23_P127781 & NM_006552 & $S C G B 1 D 1$ & Secretoglobin, family $1 \mathrm{D}$, member 1 & -6.77 & $1.26 \mathrm{E}-04$ \\
\hline A_32_P234405 & CK570316 & $\mathrm{N} / \mathrm{A}$ & & -6.62 & $1.26 \mathrm{E}-04$ \\
\hline A_23_P150555 & NM_006551 & $S C G B 1 D 2$ & Secretoglobin, family 1D, member 2 & -6.51 & $1.26 \mathrm{E}-04$ \\
\hline A_23_P12533 & NM_052997 & $A N K R D 30 A$ & Ankyrin repeat domain $30 \mathrm{~A}$ & -6.44 & $1.26 \mathrm{E}-04$ \\
\hline A_23_P8702 & NM_002652 & $P I P$ & Prolactin-induced protein & -6.34 & $1.26 \mathrm{E}-04$ \\
\hline A_23_P501010 & NM_000494 & COL17A1 & Collagen, type XVII, $\alpha 1$ & -5.69 & $1.26 \mathrm{E}-04$ \\
\hline A_24_P844984 & NM_002644 & $P I G R$ & Polymeric immunoglobulin receptor & -5.55 & $1.26 \mathrm{E}-04$ \\
\hline A_32_P216520 & NM_007191 & $W I F 1$ & WNT inhibitory factor 1 & -5.53 & $1.26 \mathrm{E}-04$ \\
\hline A_23_P71364 & NM_015886 & PII5 & Peptidase inhibitor 15 & -5.33 & $1.26 \mathrm{E}-04$ \\
\hline A_24_P273756 & NM_003722 & TP63 & Tumor protein $\mathrm{p} 63$ & -5.11 & $1.26 \mathrm{E}-04$ \\
\hline A_23_P132619 & NM_000916 & OXTR & Oxytocin receptor & -4.89 & $1.26 \mathrm{E}-04$ \\
\hline A_32_P111873 & BQ432543 & $\mathrm{N} / \mathrm{A}$ & & -4.88 & $1.26 \mathrm{E}-04$ \\
\hline A_32_P23272 & N/A & $\mathrm{N} / \mathrm{A}$ & & -4.85 & $1.26 \mathrm{E}-04$ \\
\hline A_24_P643776 & $\mathrm{N} / \mathrm{A}$ & $\mathrm{N} / \mathrm{A}$ & & -4.74 & $1.26 \mathrm{E}-04$ \\
\hline A_23_P136777 & NM_001647 & $A P O D$ & Apolipoprotein D & -4.71 & $1.26 \mathrm{E}-04$ \\
\hline A_23_P9711 & NM_006040 & HS3ST4 & $\begin{array}{l}\text { Heparan sulfate (glucosamine) 3-O- } \\
\text { sulfotransferase } 4\end{array}$ & -4.58 & $1.26 \mathrm{E}-04$ \\
\hline A_23_P305292 & NR_027180 & LOC728264 & Hypothetical LOC728264 & -4.57 & $1.26 \mathrm{E}-04$ \\
\hline A_23_P159974 & NM_033495 & KLHL13 & Kelch-like 13 (Drosophila) & -4.55 & $1.26 \mathrm{E}-04$ \\
\hline A_23_P105144 & NM_020974 & SCUBE2 & $\begin{array}{l}\text { Signal peptide, CUB domain, } \\
\text { EGF-like } 2\end{array}$ & -4.51 & $1.26 \mathrm{E}-04$ \\
\hline A_32_P14253 & N/A & N/A & & -4.47 & $1.26 \mathrm{E}-04$ \\
\hline A_23_P327380 & NM_003722 & TP63 & Tumor protein p63 & -4.45 & $1.26 \mathrm{E}-04$ \\
\hline A_23_P337270 & AK057247 & $\mathrm{N} / \mathrm{A}$ & & -4.43 & $1.26 \mathrm{E}-04$ \\
\hline A_23_P420442 & NM_153618 & SEMAGD & Sema domain, transmembrane & -4.34 & $1.26 \mathrm{E}-04$ \\
\hline
\end{tabular}

$\begin{array}{lll}\text { A_23_P8812 } & \text { N/A } & \text { N/A } \\ \text { A_23_P160377 } & \text { NM_003462 } & \text { DNALI1 } \\ \text { A_24_P92680 } & \text { AK093340 } & \text { LOC100132116 } \\ \text { A_23_P216779 } & \text { NM_001007097 } & \text { NTRK2 } \\ & & \\ \text { A_23_P148249 } & \text { NM_024817 } & \text { THSD4 } \\ & & \\ \text { A_23_P206920 } & \text { NM_001040114 } & \text { MYH11 } \\ \text { A_32_P154473 } & \text { NM_004522 } & \text { KIF5C } \\ \text { A_23_P128362 } & \text { NM_206819 } & \text { MYBPC1 } \\ \text { A_23_P83381 } & \text { NM_001143962 } & \text { CAPN8 } \\ \text { A_23_P397208 } & \text { NM_000848 } & \text { GSTM2 } \\ \text { A_23_P503072 } & \text { NM_148672 } & \text { CCL28 } \\ \text { A_23_P143068 } & \text { NM_024726 } & \text { IQCA1 } \\ \text { A_24_P829209 } & \text { AK096334 } & \text { LOC285944 } \\ \text { A_23_P394246 } & & \text { GPR81 } \\ \text { A_24_P34186 } & \text { NM_004010 } & \text { DMD } \\ \text { A_23_P303087 } & \text { NM_002825 } & \text { PTN } \\ \text { A_24_P243749 } & \text { NM_002612 } & \text { PDK4 }\end{array}$

domain (TM), and cytoplasmic

domain, (semaphorin) 6D

Dynein, axonemal, light intermediate $\quad-4.26 \quad 1.26 \mathrm{E}-04$

chain 1

Hypothetical LOC100132116 $\quad-4.23 \quad 1.26 \mathrm{E}-04$

Neurotrophic tyrosine kinase, $\quad-4.23 \quad 1.26 \mathrm{E}-04$

receptor, type 2

Thrombospondin, type I, domain $\quad-4.18 \quad 1.26 \mathrm{E}-04$

containing 4

Myosin, heavy chain 11, smooth muscle $\quad-4.13 \quad 1.26 \mathrm{E}-04$

Kinesin family member 5C $\quad-4.13 \quad 1.26 \mathrm{E}-04$

Myosin binding protein C, slow type $\quad-4.11 \quad 3.41 \mathrm{E}-04$

$\begin{array}{lll}\text { Calpain } 8 & -4.08 & 1.26 \mathrm{E}-04\end{array}$

Glutathione S-transferase mu 2 (muscle) $\quad-4.07 \quad 1.26 \mathrm{E}-04$

Chemokine (C-C motif) ligand $28 \quad-4.03 \quad 1.26 \mathrm{E}-04$

IQ motif containing with AAA domain $1 \quad-4.01 \quad 1.26 \mathrm{E}-04$

Hypothetical protein LOC285944 $\quad-3.99 \quad 2.33 \mathrm{E}-04$

$\mathrm{G}$ protein-coupled receptor $81 \quad-3.96 \quad 1.26 \mathrm{E}-04$

Dystrophin $\quad-3.96 \quad 1.26 \mathrm{E}-04$

Pleiotrophin $\quad-3.95 \quad 1.26 \mathrm{E}-04$

Pyruvate dehydrogenase kinase, $\quad-3.94 \quad 1.26 \mathrm{E}-04$ 
Table III. Continued.

\begin{tabular}{|c|c|c|c|c|c|}
\hline Probe ID & Accession no. & Symbol & Gene name & $\begin{array}{l}\text { Fold change } \\
\qquad(\log )\end{array}$ & P-value \\
\hline A_32_P39944 & AK095791 & N/A & & -3.82 & $1.26 \mathrm{E}-04$ \\
\hline A_23_P217379 & NM_033641 & COLAA6 & Collagen, type IV, $\alpha 6$ & -3.8 & $1.26 \mathrm{E}-04$ \\
\hline A_23_P407565 & NM_001337 & $C X 3 C R 1$ & Chemokine (C-X3-C motif) receptor 1 & -3.76 & $1.26 \mathrm{E}-04$ \\
\hline A_23_P373464 & NM_002285 & $A F F 3$ & AF4/FMR2 family, member 3 & -3.75 & $1.26 \mathrm{E}-04$ \\
\hline A_32_P183765 & NM_005235 & $E R B B 4$ & $\begin{array}{l}\text { v-erb-a erythroblastic leukemia viral } \\
\text { oncogene homolog } 4 \text { (avian) }\end{array}$ & -3.75 & $1.26 \mathrm{E}-04$ \\
\hline A_23_P145514 & NM_014432 & IL2ORA & Interleukin 20 receptor, $\alpha$ & -3.75 & $1.26 \mathrm{E}-04$ \\
\hline A_24_P870620 & NM_002825 & $P T N$ & Pleiotrophin & -3.74 & 2.33E-04 \\
\hline A_32_P154361 & N/A & $\mathrm{N} / \mathrm{A}$ & & -3.73 & $1.26 \mathrm{E}-04$ \\
\hline A_24_P330633 & NM_000353 & $T A T$ & Tyrosine aminotransferase & -3.72 & $1.26 \mathrm{E}-04$ \\
\hline A_23_P360777 & NM_013960 & $N R G 1$ & Neuregulin 1 & -3.72 & $1.26 \mathrm{E}-04$ \\
\hline A_23_P253982 & NM_002141 & HOXA4 & Homeobox A4 & -3.69 & $1.26 \mathrm{E}-04$ \\
\hline A_32_P114475 & N/A & N/A & & -3.68 & $1.26 \mathrm{E}-04$ \\
\hline A_32_P221774 & BX099483 & N/A & & -3.66 & $1.26 \mathrm{E}-04$ \\
\hline A_23_P212608 & NM_022131 & CLSTN2 & Calsyntenin 2 & -3.66 & 2.33E-04 \\
\hline A_23_P254165 & NM_021785 & $R A I 2$ & Retinoic acid induced 2 & -3.65 & $1.26 \mathrm{E}-04$ \\
\hline A_24_P794447 & NR_024430 & LOC399959 & Hypothetical LOC399959 & -3.64 & $1.26 \mathrm{E}-04$ \\
\hline A_23_P149517 & NM_002644 & $P I G R$ & Polymeric immunoglobulin receptor & -3.64 & $1.26 \mathrm{E}-04$ \\
\hline A_24_P904484 & NR_024344 & $L O C 283174$ & Hypothetical LOC283174 & -3.62 & $1.26 \mathrm{E}-04$ \\
\hline A_32_P194423 & $\mathrm{N} / \mathrm{A}$ & N/A & & -3.62 & $1.26 \mathrm{E}-04$ \\
\hline A_23_P371495 & NM_175861 & TMTC1 & $\begin{array}{l}\text { Transmembrane and tetratricopeptide } \\
\text { repeat containing } 1\end{array}$ & -3.6 & 2.33E-04 \\
\hline A_23_P134162 & NM_016356 & $D C D C 2$ & Doublecortin domain containing 2 & -3.58 & $1.26 \mathrm{E}-04$ \\
\hline A_32_P232455 & NM_178840 & C1orf64 & Chromosome 1 open reading frame 64 & -3.58 & $1.26 \mathrm{E}-04$ \\
\hline A_24_P318160 & NM_014903 & NAV3 & Neuron navigator 3 & -3.57 & $1.26 \mathrm{E}-04$ \\
\hline A_23_P59388 & NM_001723 & $D S T$ & Dystonin & -3.56 & $1.26 \mathrm{E}-04$ \\
\hline A_23_P399217 & NM_153445 & OR5P3 & $\begin{array}{l}\text { Olfactory receptor, family } 5 \text {, subfamily } \mathrm{P} \text {, } \\
\text { member } 3\end{array}$ & -3.56 & $1.26 \mathrm{E}-04$ \\
\hline A_23_P309739 & NM_000125 & ESR1 & Estrogen receptor 1 & -3.53 & $1.26 \mathrm{E}-04$ \\
\hline A_24_P608007 & AK022390 & N/A & & -3.53 & $1.26 \mathrm{E}-04$ \\
\hline A_23_P501538 & NM_153631 & HOXA3 & Homeobox A3 & -3.52 & $1.26 \mathrm{E}-04$ \\
\hline A_24_P602871 & NM_001030060 & SAMD5 & Sterile $\alpha$ motif domain containing 5 & -3.52 & $1.26 \mathrm{E}-04$ \\
\hline A_23_P136433 & N/A & $\mathrm{N} / \mathrm{A}$ & & -3.51 & $1.26 \mathrm{E}-04$ \\
\hline A_23_P30294 & NM_001801 & CDO1 & Cysteine dioxygenase, type I & -3.48 & $1.26 \mathrm{E}-04$ \\
\hline A_23_P218928 & NM_016613 & FAM198B & $\begin{array}{l}\text { Family with sequence similarity } 198, \\
\text { member B }\end{array}$ & -3.47 & $1.26 \mathrm{E}-04$ \\
\hline A_23_P154627 & XM_002345419 & TSHZ2 & Teashirt zinc finger homeobox 2 & -3.47 & $1.26 \mathrm{E}-04$ \\
\hline A_23_P303833 & NM_174934 & $S C N 4 B$ & Sodium channel, voltage-gated, type IV, $\beta$ & -3.45 & $1.26 \mathrm{E}-04$ \\
\hline A_24_P930088 & XM_002342181 & LOC 100286909 & Hypothetical protein LOC100286909 & -3.45 & $1.26 \mathrm{E}-04$ \\
\hline A_32_P81623 & AA514833 & N/A & & -3.42 & $1.26 \mathrm{E}-04$ \\
\hline A_24_P923028 & ВС020707 & $T A T$ & Tyrosine aminotransferase & -3.41 & $1.26 \mathrm{E}-04$ \\
\hline A_23_P58869 & NR_002932 & $L O C 442245$ & Glutathione S-transferase mu 2 pseudogene & -3.4 & $1.26 \mathrm{E}-04$ \\
\hline A_23_P2271 & NM_198965 & PTHLH & Parathyroid hormone-like hormone & -3.4 & $1.26 \mathrm{E}-04$ \\
\hline A_32_P43664 & & & & -3.39 & $1.26 \mathrm{E}-04$ \\
\hline A_32_P16007 & NM_207355 & POTEB & POTE ankyrin domain family, member B & -3.39 & $1.26 \mathrm{E}-04$ \\
\hline A_23_P94840 & NM_130897 & $D Y N L R B 2$ & Dynein, light chain, roadblock-type 2 & -3.38 & $1.26 \mathrm{E}-04$ \\
\hline A_24_P5153 & NM_024817 & THSD4 & Thrombospondin, type I, domain & -3.38 & $1.26 \mathrm{E}-04$ \\
\hline
\end{tabular}


Table III. Continued.

\begin{tabular}{|c|c|c|c|c|c|}
\hline Probe ID & Accession no. & Symbol & Gene name & $\begin{array}{l}\text { Fold change } \\
\qquad(\log )\end{array}$ & P-value \\
\hline A_32_P223675 & $\mathrm{N} / \mathrm{A}$ & $\mathrm{N} / \mathrm{A}$ & & -3.37 & $1.26 \mathrm{E}-04$ \\
\hline A_24_P904845 & AK095791 & $\mathrm{N} / \mathrm{A}$ & & -3.37 & $1.26 \mathrm{E}-04$ \\
\hline A_23_P403209 & N/A & $\mathrm{N} / \mathrm{A}$ & & -3.36 & $1.26 \mathrm{E}-04$ \\
\hline A_23_P215382 & N/A & $\mathrm{N} / \mathrm{A}$ & & -3.35 & $3.41 \mathrm{E}-04$ \\
\hline A_24_P209710 & NM_004816 & FAM189A2 & Family with sequence similarity 189, member A2 & -3.35 & $1.26 \mathrm{E}-04$ \\
\hline A_23_P167168 & NM_144646 & IGJ & $\begin{array}{l}\text { Immunoglobulin } \mathbf{J} \text { polypeptide, linker protein for } \\
\text { immunoglobulin } \alpha \text { and mu polypeptides }\end{array}$ & -3.34 & $1.26 \mathrm{E}-04$ \\
\hline A_24_P70183 & NM_001040113 & MYH11 & Myosin, heavy chain 11, smooth muscle & -3.32 & $1.26 \mathrm{E}-04$ \\
\hline A_23_P216361 & NM_021110 & COL14A1 & collagen, type XIV, $\alpha 1$ & -3.32 & $1.26 \mathrm{E}-04$ \\
\hline A_23_P113351 & NM_004684 & SPARCLI & SPARC-like 1 (hevin) & -3.31 & $1.26 \mathrm{E}-04$ \\
\hline A_32_P17145 & N/A & N/A & & -3.31 & $1.26 \mathrm{E}-04$ \\
\hline A_23_P35414 & NM_005398 & $P P P 1 R 3 \mathrm{C}$ & $\begin{array}{l}\text { Protein phosphatase } 1 \text {, regulatory (inhibitor) } \\
\text { subunit } 3 \mathrm{C}\end{array}$ & -3.29 & $1.26 \mathrm{E}-04$ \\
\hline A_23_P31945 & NM_033439 & IL33 & Interleukin 33 & -3.27 & $1.26 \mathrm{E}-04$ \\
\hline A_23_P204630 & NM_021229 & NTN4 & Netrin 4 & -3.26 & $1.26 \mathrm{E}-04$ \\
\hline A_23_P501831 & NM_032385 & C5orf4 & Chromosome 5 open reading frame 4 & -3.26 & $1.26 \mathrm{E}-04$ \\
\hline A_23_P200015 & NM_174858 & $A K 5$ & Adenylate kinase 5 & -3.26 & $1.26 \mathrm{E}-04$ \\
\hline A_24_P802145 & NM_005544 & IRS1 & Insulin receptor substrate 1 & -3.26 & $1.26 \mathrm{E}-04$ \\
\hline A_24_P251969 & NM_000800 & $F G F 1$ & Fibroblast growth factor 1 (acidic) & -3.24 & $1.26 \mathrm{E}-04$ \\
\hline A_32_P228618 & NM_001003793 & $R B M S 3$ & $\begin{array}{l}\text { RNA binding motif, single stranded interacting } \\
\text { protein }\end{array}$ & -3.23 & $1.26 \mathrm{E}-04$ \\
\hline A_23_P125233 & NM_001299 & $C N N 1$ & Calponin 1 , basic, smooth muscle & -3.22 & 2.33E-04 \\
\hline A_23_P500998 & NM_152739 & HOXА9 & Homeobox A9 & -3.19 & 2.33E-04 \\
\hline A_23_P83838 & NM_004056 & CA8 & Carbonic anhydrase VIII & -3.19 & $1.26 \mathrm{E}-04$ \\
\hline A_24_P911950 & N/A & N/A & & -3.17 & $1.26 \mathrm{E}-04$ \\
\hline A_23_P159952 & NM_018476 & $B E X 1$ & Brain expressed, X-linked 1 & -3.17 & $1.26 \mathrm{E}-04$ \\
\hline A_23_P45185 & NM_004469 & $F I G F$ & $\begin{array}{l}\text { c-fos induced growth factor (vascular endothelial } \\
\text { growth factor D) }\end{array}$ & -3.16 & 2.33E-04 \\
\hline A_23_P14083 & NM_181847 & AMIGO2 & Adhesion molecule with Ig-like domain 2 & -3.16 & $1.26 \mathrm{E}-04$ \\
\hline A_24_P920366 & N/A & N/A & & -3.14 & $1.26 \mathrm{E}-04$ \\
\hline A_24_P167668 & NM_000428 & $L T B P 2$ & $\begin{array}{l}\text { Latent transforming growth factor } \beta \text { binding } \\
\text { protein } 2\end{array}$ & -3.12 & $1.26 \mathrm{E}-04$ \\
\hline A_32_P161033 & ВC043411 & N/A & & -3.11 & $1.26 \mathrm{E}-04$ \\
\hline A_23_P348159 & NM_020388 & $D S T$ & Dystonin & -3.11 & $1.26 \mathrm{E}-04$ \\
\hline A_32_P89415 & N/A & N/A & & -3.1 & $1.26 \mathrm{E}-04$ \\
\hline A_23_P165778 & NM_024101 & $M L P H$ & Melanophilin & -3.08 & $1.26 \mathrm{E}-04$ \\
\hline A_32_P168701 & N/A & N/A & & -3.07 & $3.41 \mathrm{E}-04$ \\
\hline A_32_P78491 & NM_004956 & ETV1 & ets variant 1 & -3.06 & $1.26 \mathrm{E}-04$ \\
\hline A_24_P87036 & NM_018043 & ANO1 & Anoctamin 1 , calcium activated chloride channel & -3.06 & $1.26 \mathrm{E}-04$ \\
\hline A_24_P912799 & NM_003966 & SEMA5A & $\begin{array}{l}\text { Sema domain, seven thrombospondin repeats } \\
\text { (type } 1 \text { and type } 1 \text {-like), transmembrane domain } \\
\text { (TM) and short cytoplasmic domain, } \\
\text { (semaphorin) 5A }\end{array}$ & -3.06 & $1.26 \mathrm{E}-04$ \\
\hline A_23_P315364 & NM_002089 & CXCL2 & Chemokine (C-X-C motif) ligand 2 & -3.05 & $1.26 \mathrm{E}-04$ \\
\hline A_24_P71341 & NM_001461 & FMO5 & Flavin containing monooxygenase 5 & -3.05 & 2.33E-04 \\
\hline A_32_P199796 & NM_004023 & $D M D$ & Dystrophin & -3.05 & 2.33E-04 \\
\hline A_32_P179998 & NM_033053 & DMRTC1 & DMRT-like family C1 & -3.04 & $1.26 \mathrm{E}-04$ \\
\hline A_32_P17984 & N/A & N/A & & -3.04 & $1.26 \mathrm{E}-04$ \\
\hline
\end{tabular}


Table III. Continued.

Probe ID Accession no. Symbol Gene nate

Fold change P-value

$(\log )$

A_23_P138938 NM_000926

A_23_P18559 NM_003866

A_23_P124946 NM_153610

A_23_P212241 NM_006614

A_23_P156402 NM_003551

A_23_P150053 NM_001613

A_32_P58912 N/A

A_32_P216841

NM_145263

A_23_P257087

NM_002612

A_23_P110686

NM_003714

A_23_P369994

NM_004734

A_23_P422831

NM_004816

A_24_P325992

NM_002310

A_23_P387000

NM_173683

A_32_P83811

NM_001136570

A_32_P44210

BX538299

A_24_P918317

NM_015881

A_23_P203957

NM_175861

A_23_P30217

NM_052863

A_23_P77066

NM_022807

A_32_P109242

AK055302

A_24_P937265

N/A

A_32_P97968

N/A

A_32_P85684

AA069768

A_23_P385067

NM_053277

A_23_P82868

NM_000930

A_32_P108396

N/A

A_23_P148345

A_24_P314477

A_24_P895836

A_23_P171074

A_23_P9135

A_23_P372234

A_23_P393099

A_23_P113701

A_23_P10995

NM_194463

NM_178012

$\mathrm{N} / \mathrm{A}$

NM_004867

NM_033655

NM_001218

NM_003226

NM_002607

NM_014483

A_24_P269006

NM_001182

A_23_P415533

AK054879

A_23_P216225

NM_004430

A_24_P101282

$\mathrm{N} / \mathrm{A}$

A_32_P72541

$\mathrm{N} / \mathrm{A}$

A_24_P299474

NM_001122679
INPP4B

Progesterone receptor

$-3.04$

$-3.03$

$105 \mathrm{kDa}$

CMYA5 Cardiomyopathy associated 5

CHL1 Cell adhesion molecule with homology to

L1CAM (close homolog of L1)

NME5 Non-metastatic cells 5, protein expressed in

(nucleoside-diphosphate kinase)

ACTA2 Actin, $\alpha 2$, smooth muscle, aorta

$\mathrm{N} / \mathrm{A}$

SPATA18

Spermatogenesis associated 18 homolog (rat)

PDK4

STC2

Pyruvate dehydrogenase kinase, isozyme 4

DCLK1

Stanniocalcin 2

FAM189A2 Family with sequence similarity 189, member A2

LIFR

XKR6

FAM47E

N/A

DKK3

TMTC1

$S C G B 3 A 1$

SNRPN

CSRNP3

$\mathrm{N} / \mathrm{A}$

$\mathrm{N} / \mathrm{A}$

N/A

CLIC6

Chloride intracellular channel 6

PLAT

N/A

RNF 128

Plasminogen activator, tissue

$T U B B 2 B$

N/A

ITM2A

CNTNAP3

CA12

TFF3

PDGFA

RBMS3

Ring finger protein 128

Tubulin, $\beta$ 2B

$\mathrm{XK}$, Kell blood group complex subunit-related family, member 6

Family with sequence similarity 47 , member E

Dickkopf homolog 3 (Xenopus laevis)

Transmembrane and tetratricopeptide repeat containing 1

Secretoglobin, family 3A, member 1

Small nuclear ribonucleoprotein polypeptide N

Cysteine-serine-rich nuclear protein 3

Integral membrane protein $2 \mathrm{~A}$

Contactin associated protein-like 3

Carbonic anhydrase XII

Trefoil factor 3 (intestinal)

Platelet-derived growth factor $\alpha$ polypeptide

RNA binding motif, single stranded interacting protein

ALDH7A1 Aldehyde dehydrogenase 7 family, member A1

N/A

EGR3 Early growth response 3

$\mathrm{N} / \mathrm{A}$

$\mathrm{N} / \mathrm{A}$

ODZ2
$-3.03$

1.26E-04

$-3.03$

$1.26 \mathrm{E}-04$

$-3.02$

1.26E-04

$-3.02$

1.26E-04

$-3.02$

$1.26 \mathrm{E}-04$

$-3.01$

2.33E-04

$-3.01 \quad 1.26 \mathrm{E}-04$

$-3$

$-2.99$

$1.26 \mathrm{E}-04$

$-2.98$

2.33E-04

$-2.98$

$1.26 \mathrm{E}-04$

$-2.98$

$1.26 \mathrm{E}-04$

$-2.98$

$-2.97$

$-2.97$

$-2.96$

$-2.96$

$-2.94$

$-2.91$

$-2.91$

$-2.9$

$-2.89$

$-2.89$

$-2.88$

$-2.88$

$-2.87$

$-2.87$

$-2.87$

$-2.85$

$-2.85$

$-2.83$

$-2.82$

$-2.82$

$-2.82$

1.26E-04

$1.26 \mathrm{E}-04$

4.43E-04

3.41E-04

1.26E-04

1.26E-04

$1.26 \mathrm{E}-04$

$1.26 \mathrm{E}-04$

1.26E-04

$1.26 \mathrm{E}-04$

4.43E-04

$1.26 \mathrm{E}-04$

$1.26 \mathrm{E}-04$

$1.26 \mathrm{E}-04$

$1.26 \mathrm{E}-04$

$1.26 \mathrm{E}-04$

$1.26 \mathrm{E}-04$

4.43E-04

$1.26 \mathrm{E}-04$

2.33E-04

$1.26 \mathrm{E}-04$

$1.26 \mathrm{E}-04$

$-2.81$

1.26E-04

$-2.81$

$1.26 \mathrm{E}-04$

$-2.8$

$1.26 \mathrm{E}-04$

$-2.8$

$-2.8$

$1.26 \mathrm{E}-04$

$-2.8$ 
Table III. Continued.

\begin{tabular}{lll}
\hline Probe ID & Accession no. & \multicolumn{1}{c}{ Symbol } \\
& & \\
\hline A_23_P416395 & NM_003714 & STC2 \\
A_23_P40415 & NM_007038 & ADAMTS5 \\
& & \\
A_32_P3545 & XM_002345868 & LOC100131504 \\
A_23_P106405 & NM_002487 & NDN \\
A_23_P405129 & NM_000428 & LTBP2 \\
& & \\
A_24_P237804 & NM_174981 & POTED \\
A_23_P89780 & NM_198129 & LAMA3 \\
A_23_P213415 & NM_003966 & SEMA5A
\end{tabular}

$\begin{array}{lll}\text { A_24_P397386 } & \text { NM_002310 } & \text { LIFR } \\ \text { A_23_P73297 } & \text { NM_004742 } & \text { MAGI1 } \\ & & \\ \text { A_23_P165783 } & \text { NM_024101 } & \text { MLPH } \\ \text { A_23_P212061 } & \text { NM_007289 } & \text { MME } \\ \text { A_23_P75056 } & \text { NM_001002295 } & \text { GATA3 } \\ \text { A_24_P748377 } & \text { CR749529 } & \\ \text { A_24_P810476 } & & \text { NTRK3 } \\ \text { A_32_P60606 } & \text { AL713753 } & \text { DKFZp667F0711 } \\ \text { A_32_P200697 } & \text { NM_181709 } & \text { FAM101A }\end{array}$

\section{A_24_P84220 NR_027995 LOC284232}

A_23_P157914 NM_153267

$M A M D C 2$

A_24_P393596 N/A

$\mathrm{N} / \mathrm{A}$

A_32_P25419 N/A N/A

A_24_P169873 N/A N/A

A_24_P358534 N/A N/A

A_32_P34750 AV702101 N/A

A_32_P9941 NM_007191 WIF1

A_23_P335143 U81001 SNRPN

$\begin{array}{lll}\text { A_23_P56855 } & \text { NM_001137671 } & \text { POTEC } \\ \text { A_32_P59837 } & \text { AK091914 } & \text { N/A } \\ \text { A_24_P737553 } & \text { AK023774 } & \text { N/A } \\ \text { A_23_P204286 } & \text { NM_000900 } & \text { MGP } \\ \text { A_24_P725895 } & \text { BE218249 } & \text { N/A } \\ \text { A_32_P4337 } & \text { N/A } & \text { N/A } \\ \text { A_23_P154400 } & \text { NM_001042467 } & \text { MLPH } \\ \text { A_23_P29800 } & \text { NM_005602 } & \text { CLDN11 } \\ \text { A_23_P156025 } & \text { NM_033267 } & \text { IRX2 } \\ \text { A_32_P193091 } & \text { N/A } & \text { N/A } \\ \text { A_23_P83857 } & \text { NM_000240 } & \text { MAOA } \\ \text { A_32_P355396 } & \text { NM_014844 } & \text { TECPR2 } \\ \text { A_32_P214565 } & \text { BU928689 } & \text { N/A }\end{array}$

Stanniocalcin 2

ADAM metallopeptidase with

thrombospondin type 1 motif, 5

Hypothetical LOC100131504

Necdin homolog (mouse)

Latent transforming growth factor $\beta$ binding protein 2

POTE ankyrin domain family, member D

Laminin, $\alpha 3$

Sema domain, seven thrombospondin

repeats (type 1 and type 1-like),

transmembrane domain (TM) and short

cytoplasmic domain, (semaphorin) 5A

Leukemia inhibitory factor receptor $\alpha$

Membrane associated guanylate kinase,

WW and PDZ domain containing 1

Melanophilin

Membrane metallo-endopeptidase

GATA binding protein 3

Neurotrophic tyrosine kinase, receptor, type 3

Hypothetical protein DKFZp667F0711

Family with sequence similarity 101 ,

member A

Ankyrin repeat domain 20 family,

member A2 pseudogene

MAM domain containing 2

$1.26 \mathrm{E}-04$

$1.26 \mathrm{E}-04$

$-2.76$

1.26E-04

$-2.76$

$-2.76$

$-2.75$

$-2.74$

$-2.74$

$-2.73$

$-2.73$

$-2.71$

$-2.71$

$-2.7$

$-2.7$

$-2.69$

$-2.69$

WNT inhibitory factor 1

Small nuclear ribonucleoprotein

$-2.68$

$-2.67$

polypeptide $\mathrm{N}$

POTE ankyrin domain family, member $\mathrm{C}$

$1.26 \mathrm{E}-04$

Matrix Gla protein

$-2.65$

$-2.63$

$-2.63$

Melanophilin

$-2.62$

$-2.61$

$-2.61$

Iroquois homeobox 2

Monoamine oxidase A

$-2.61$

$-2.6$

$-2.6$

$-2.6$

1.26E-04

1.26E-04

4.43E-04

$1.26 \mathrm{E}-04$

1.26E-04

$1.26 \mathrm{E}-04$

$1.26 \mathrm{E}-04$

3.41E-04

$1.26 \mathrm{E}-04$

1.26E-04

2.33E-04

3.41E-04

$1.26 \mathrm{E}-04$

4.43E-04

$1.26 \mathrm{E}-04$

1.26E-04

$1.26 \mathrm{E}-04$

$1.26 \mathrm{E}-04$

$1.26 \mathrm{E}-04$

3.41E-04

1.26E-04

2.33E-04

1.26E-04

Tectonin $\beta$-propeller repeat containing 2
$1.26 \mathrm{E}-04$

2.33E-04

1.26E-04

$1.26 \mathrm{E}-04$

$1.26 \mathrm{E}-04$

$1.26 \mathrm{E}-04$

$1.26 \mathrm{E}-04$

$1.26 \mathrm{E}-04$

1.26E-04

$1.26 \mathrm{E}-04$

$1.26 \mathrm{E}-04$

$1.26 \mathrm{E}-04$ 
Table III. Continued.

\begin{tabular}{|c|c|c|c|c|c|}
\hline Probe ID & Accession no. & Symbol & Gene name & $\begin{array}{l}\text { Fold change } \\
\qquad(\log )\end{array}$ & P-value \\
\hline A_24_P468950 & AK021439 & N/A & & -2.6 & $1.26 \mathrm{E}-04$ \\
\hline A_24_P683583 & $\mathrm{N} / \mathrm{A}$ & $\mathrm{N} / \mathrm{A}$ & & -2.6 & $1.26 \mathrm{E}-04$ \\
\hline A_23_P203558 & NM_000518 & $H B B$ & Hemoglobin, $\beta$ & -2.6 & 2.33E-04 \\
\hline A_32_P140153 & $\mathrm{N} / \mathrm{A}$ & N/A & & -2.6 & $1.26 \mathrm{E}-04$ \\
\hline A_32_P124461 & AK129743 & N/A & & -2.59 & $1.26 \mathrm{E}-04$ \\
\hline A_23_P136026 & AK128476 & N/A & & -2.59 & $1.26 \mathrm{E}-04$ \\
\hline A_23_P28295 & NM_004525 & $L R P 2$ & Low density lipoprotein-related protein 2 & -2.59 & 4.43E-04 \\
\hline A_24_P586712 & NM_198485 & TPRG1 & Tumor protein p63 regulated 1 & -2.58 & $1.26 \mathrm{E}-04$ \\
\hline A_23_P139500 & NM_030762 & BHLHE41 & Basic helix-loop-helix family, member e41 & -2.58 & $1.26 \mathrm{E}-04$ \\
\hline A_23_P121480 & NM_001004196 & $C D 200$ & CD200 molecule & -2.58 & $1.26 \mathrm{E}-04$ \\
\hline A_23_P32577 & NM_080759 & $D A C H 1$ & Dachshund homolog 1 (Drosophila) & -2.58 & $1.26 \mathrm{E}-04$ \\
\hline A_23_P315815 & NM_004495 & $N R G 1$ & Neuregulin 1 & -2.58 & $1.26 \mathrm{E}-04$ \\
\hline A_23_P93772 & NM_019102 & HOXA5 & Homeobox A5 & -2.58 & $1.26 \mathrm{E}-04$ \\
\hline A_32_P150748 & CR749529 & N/A & & -2.58 & $1.26 \mathrm{E}-04$ \\
\hline A_32_P204959 & N/A & N/A & & -2.58 & $1.26 \mathrm{E}-04$ \\
\hline A_23_P363149 & N/A & N/A & & -2.57 & 4.43E-04 \\
\hline A_23_P41487 & NM_015130 & $T B C 1 D 9$ & $\begin{array}{l}\text { TBC1 domain family, member } 9 \text { (with GRAM } \\
\text { domain) }\end{array}$ & -2.57 & $1.26 \mathrm{E}-04$ \\
\hline A_23_P257296 & NM_003226 & TFF3 & Trefoil factor 3 (intestinal) & -2.56 & $3.41 \mathrm{E}-04$ \\
\hline A_23_P250735 & NM_175709 & $C B X 7$ & Chromobox homolog 7 & -2.56 & $1.26 \mathrm{E}-04$ \\
\hline A_24_P189516 & NM_001609 & $A C A D S B$ & $\begin{array}{l}\text { acyl-coenzyme A dehydrogenase, short/ } \\
\text { branched chain }\end{array}$ & -2.56 & $1.26 \mathrm{E}-04$ \\
\hline A_23_P253012 & NM_017577 & GRAMD1C & GRAM domain containing $1 \mathrm{C}$ & -2.56 & $1.26 \mathrm{E}-04$ \\
\hline A_24_P179244 & XM_001723863 & LOC 100128979 & Hypothetical protein LOC100128979 & -2.55 & $1.26 \mathrm{E}-04$ \\
\hline A_32_P117846 & $\mathrm{N} / \mathrm{A}$ & N/A & & -2.55 & $1.26 \mathrm{E}-04$ \\
\hline A_32_P42224 & BX097190 & N/A & & -2.55 & 2.33E-04 \\
\hline A_24_P119665 & NM_001128933 & SYNPO2 & Synaptopodin 2 & -2.54 & $1.26 \mathrm{E}-04$ \\
\hline A_32_P105825 & NM_001584 & MPPED2 & Metallophosphoesterase domain containing 2 & -2.54 & $3.41 \mathrm{E}-04$ \\
\hline A_24_P225679 & NM_005544 & IRS1 & Insulin receptor substrate 1 & -2.54 & $1.26 \mathrm{E}-04$ \\
\hline A_32_P226907 & $\mathrm{N} / \mathrm{A}$ & N/A & & -2.54 & $1.26 \mathrm{E}-04$ \\
\hline A_23_P356581 & NM_022370 & $\mathrm{ROBO3}$ & $\begin{array}{l}\text { Roundabout, axon guidance receptor, } \\
\text { homolog } 3 \text { (Drosophila) }\end{array}$ & -2.53 & $1.26 \mathrm{E}-04$ \\
\hline A_32_P221096 & AW015426 & N/A & & -2.53 & $1.26 \mathrm{E}-04$ \\
\hline A_23_P106016 & NM_002742 & PRKD1 & Protein kinase D1 & -2.52 & $1.26 \mathrm{E}-04$ \\
\hline A_32_P210193 & $\mathrm{N} / \mathrm{A}$ & N/A & & -2.52 & $1.26 \mathrm{E}-04$ \\
\hline A_32_P38436 & $\mathrm{N} / \mathrm{A}$ & N/A & & -2.52 & $1.26 \mathrm{E}-04$ \\
\hline A_24_P512775 & N/A & N/A & & -2.52 & $1.26 \mathrm{E}-04$ \\
\hline A_23_P151529 & NR_023938 & C14orf132 & Chromosome 14 open reading frame 132 & -2.52 & $1.26 \mathrm{E}-04$ \\
\hline A_32_P235568 & AK125221 & N/A & & -2.52 & $1.26 \mathrm{E}-04$ \\
\hline A_23_P71270 & NM_001185 & $A Z G P 1$ & $\alpha$-2-glycoprotein 1 , zinc-binding & -2.52 & 4.43E-04 \\
\hline A_24_P650425 & $\mathrm{N} / \mathrm{A}$ & $\mathrm{N} / \mathrm{A}$ & & -2.51 & $1.26 \mathrm{E}-04$ \\
\hline A_23_P71328 & NM_030583 & MATN2 & Matrilin 2 & -2.51 & 2.33E-04 \\
\hline A_24_P153803 & NM_020663 & RHOJ & ras homolog gene family, member $\mathbf{J}$ & -2.51 & $1.26 \mathrm{E}-04$ \\
\hline A_24_P912730 & N/A & N/A & & -2.51 & $1.26 \mathrm{E}-04$ \\
\hline A_24_P347624 & NM_022804 & SNURF & SNRPN upstream reading frame & -2.5 & $1.26 \mathrm{E}-04$ \\
\hline A_32_P52785 & NM_015345 & $D A A M 2$ & $\begin{array}{l}\text { Dishevelled associated activator of } \\
\text { morphogenesis } 2\end{array}$ & -2.5 & $3.41 \mathrm{E}-04$ \\
\hline A_23_P61042 & $\mathrm{N} / \mathrm{A}$ & N/A & & -2.5 & $1.26 \mathrm{E}-04$ \\
\hline
\end{tabular}


Table III. Continued.

\begin{tabular}{|c|c|c|c|c|}
\hline Probe ID & Accession no. & Symbol & Gene name & $\begin{array}{l}\text { Fold change } \\
\text { (log) }\end{array}$ \\
\hline
\end{tabular}

Fold change P-value $(\log )$

\begin{tabular}{|c|c|c|c|c|c|}
\hline A_23_P67661 & NM_001864 & COX7A1 & $\begin{array}{l}\text { Cytochrome c oxidase subunit VIIa polypeptide } 1 \\
\text { (muscle) }\end{array}$ & -2.49 & $1.26 \mathrm{E}-04$ \\
\hline A_23_P213486 & N/A & PARP8 & Poly(ADP-ribose) polymerase family, member 8 & -2.49 & $1.26 \mathrm{E}-04$ \\
\hline A_23_P18713 & NM_004827 & $A B C G 2$ & $\begin{array}{l}\text { ATP-binding cassette, sub-family G (WHITE), } \\
\text { member } 2\end{array}$ & -2.48 & 4.43E-04 \\
\hline A_23_P76658 & NM_052818 & $N 4 B P 2 L 1$ & NEDD4 binding protein 2-like 1 & -2.48 & $1.26 \mathrm{E}-04$ \\
\hline A_23_P96590 & NM_014710 & GPRASPl & $\begin{array}{l}\text { G protein-coupled receptor associated sorting } \\
\text { protein } 1\end{array}$ & -2.48 & $1.26 \mathrm{E}-04$ \\
\hline A_24_P460763 & AK022443 & N/A & & -2.48 & $1.26 \mathrm{E}-04$ \\
\hline A_23_P85672 & NM_006610 & $M A S P 2$ & Mannan-binding lectin serine peptidase 2 & -2.48 & $1.26 \mathrm{E}-04$ \\
\hline A_24_P416489 & N/A & $\mathrm{N} / \mathrm{A}$ & & -2.47 & $1.26 \mathrm{E}-04$ \\
\hline A_24_P321525 & NM_032918 & $R E R G$ & RAS-like, estrogen-regulated, growth inhibitor & -2.47 & $1.26 \mathrm{E}-04$ \\
\hline A_24_P256526 & ВC005914 & $S P 2$ & $\mathrm{Sp} 2$ transcription factor & -2.47 & $1.26 \mathrm{E}-04$ \\
\hline A_24_P261417 & NM_015881 & $D K K 3$ & Dickkopf homolog 3 (Xenopus laevis) & -2.47 & $1.26 \mathrm{E}-04$ \\
\hline A_23_P98369 & NM_000829 & GRIA4 & Glutamate receptor, ionotrophic, AMPA 4 & -2.47 & $1.26 \mathrm{E}-04$ \\
\hline A_23_P6818 & NM_020163 & SEMA3G & $\begin{array}{l}\text { Sema domain, immunoglobulin domain (Ig), short } \\
\text { basic domain, secreted, (semaphorin) } 3 \mathrm{G}\end{array}$ & -2.46 & $3.41 \mathrm{E}-04$ \\
\hline A_32_P100379 & N/A & N/A & & -2.46 & $1.26 \mathrm{E}-04$ \\
\hline A_23_P30163 & NR_026804 & FLJ13197 & Hypothetical FLJ13197 & -2.46 & $1.26 \mathrm{E}-04$ \\
\hline A_24_P206328 & NM_005020 & $P D E 1 C$ & $\begin{array}{l}\text { Phosphodiesterase } 1 \mathrm{C} \text {, calmodulin-dependent } \\
70 \mathrm{kDa}\end{array}$ & -2.46 & $1.26 \mathrm{E}-04$ \\
\hline A_24_P93948 & AB210045 & N/A & & -2.46 & $1.26 \mathrm{E}-04$ \\
\hline A_32_P52414 & $\mathrm{N} / \mathrm{A}$ & $\mathrm{N} / \mathrm{A}$ & & -2.45 & $1.26 \mathrm{E}-04$ \\
\hline A_23_P123228 & NM_000111 & $S L C 26 A 3$ & Solute carrier family 26 , member 3 & -2.45 & $1.26 \mathrm{E}-04$ \\
\hline A_24_P666553 & $\mathrm{N} / \mathrm{A}$ & $\mathrm{N} / \mathrm{A}$ & & -2.45 & $1.26 \mathrm{E}-04$ \\
\hline A_24_P916816 & N/A & $\mathrm{N} / \mathrm{A}$ & & -2.44 & $1.26 \mathrm{E}-04$ \\
\hline A_23_P134734 & NM_017786 & GOLSYN & Golgi-localized protein & -2.44 & $1.26 \mathrm{E}-04$ \\
\hline A_24_P296772 & NM_033256 & PPPIR14A & $\begin{array}{l}\text { Protein phosphatase } 1 \text {, regulatory (inhibitor) } \\
\text { subunit } 14 \mathrm{~A}\end{array}$ & -2.43 & $1.26 \mathrm{E}-04$ \\
\hline A_24_P267523 & NM_144613 & COX6B2 & $\begin{array}{l}\text { Cytochrome c oxidase subunit VIb polypeptide } 2 \\
\text { (testis) }\end{array}$ & -2.43 & $1.26 \mathrm{E}-04$ \\
\hline A_23_P133517 & NM_002310 & LIFR & Leukemia inhibitory factor receptor $\alpha$ & -2.43 & $1.26 \mathrm{E}-04$ \\
\hline A_24_P787680 & N/A & $\mathrm{N} / \mathrm{A}$ & & -2.43 & $1.26 \mathrm{E}-04$ \\
\hline A_32_P52829 & N/A & $\mathrm{N} / \mathrm{A}$ & & -2.43 & $3.41 \mathrm{E}-04$ \\
\hline A_23_P162047 & NM_015881 & $D K K 3$ & Dickkopf homolog 3 (Xenopus laevis) & -2.43 & $1.26 \mathrm{E}-04$ \\
\hline A_32_P185140 & BX648171 & TPM1 & Tropomyosin $1(\alpha)$ & -2.43 & $1.26 \mathrm{E}-04$ \\
\hline A_24_P319892 & NM_198274 & SMYD1 & SET and MYND domain containing 1 & -2.43 & $1.26 \mathrm{E}-04$ \\
\hline A_24_P226322 & NM_031469 & SH3BGRL2 & $\begin{array}{l}\text { SH3 domain binding glutamic acid-rich protein } \\
\text { like } 2\end{array}$ & -2.42 & $1.26 \mathrm{E}-04$ \\
\hline
\end{tabular}
like 2

Fibromodulin

$-2.41 \quad 1.26 \mathrm{E}-04$

PDGFRA Platelet-derived growth factor receptor,

$-2.41 \quad 2.33 \mathrm{E}-04$ 
Table III. Continued.

\begin{tabular}{|c|c|c|c|c|c|}
\hline Probe ID & Accession no. & Symbol & Gene name & $\begin{array}{l}\text { Fold change } \\
\qquad(\log )\end{array}$ & P-value \\
\hline A_23_P345746 & NM_199261 & TPTE & $\begin{array}{l}\text { Transmembrane phosphatase with tensin } \\
\text { homology }\end{array}$ & -2.41 & $1.26 \mathrm{E}-04$ \\
\hline A_23_P418083 & NM_181714 & $L C A 5$ & Leber congenital amaurosis 5 & -2.41 & $1.26 \mathrm{E}-04$ \\
\hline A_32_P208341 & $\mathrm{N} / \mathrm{A}$ & N/A & & -2.41 & $1.26 \mathrm{E}-04$ \\
\hline A_24_P930337 & $\mathrm{N} / \mathrm{A}$ & N/A & & -2.41 & $1.26 \mathrm{E}-04$ \\
\hline A_24_P915095 & NM_017577 & GRAMDIC & GRAM domain containing $1 \mathrm{C}$ & -2.4 & $1.26 \mathrm{E}-04$ \\
\hline A_32_P4792 & AK057820 & $\mathrm{N} / \mathrm{A}$ & & -2.4 & $1.26 \mathrm{E}-04$ \\
\hline A_24_P82032 & NM_020663 & RHOJ & ras homolog gene family, member $\mathbf{J}$ & -2.39 & 2.33E-04 \\
\hline A_23_P204296 & NM_032918 & $R E R G$ & RAS-like, estrogen-regulated, growth inhibitor & -2.38 & $1.26 \mathrm{E}-04$ \\
\hline A_24_P920712 & $\mathrm{N} / \mathrm{A}$ & $\mathrm{N} / \mathrm{A}$ & & -2.38 & 2.33E-04 \\
\hline A_24_P401185 & NM_001042784 & $C C D C 158$ & Coiled-coil domain containing 158 & -2.38 & $1.26 \mathrm{E}-04$ \\
\hline A_32_P109604 & XM_001715342 & LOC 100132733 & Similar to FLJ00310 protein & -2.37 & $1.26 \mathrm{E}-04$ \\
\hline A_24_P131173 & NM_024709 & C1orf115 & Chromosome 1 open reading frame 115 & -2.37 & 2.33E-04 \\
\hline A_24_P64241 & NM_001012421 & $A N K R D 20 A 2$ & Ankyrin repeat domain 20 family, member A2 & -2.37 & $1.26 \mathrm{E}-04$ \\
\hline A_32_P58437 & N/A & N/A & & -2.37 & $1.26 \mathrm{E}-04$ \\
\hline A_24_P602348 & $\mathrm{N} / \mathrm{A}$ & N/A & & -2.37 & $1.26 \mathrm{E}-04$ \\
\hline A_24_P135856 & NM_016124 & $R H D$ & Rh blood group, D antigen & -2.37 & 1.26E-04 \\
\hline A_23_P333038 & NM_025145 & C10orf79 & Chromosome 10 open reading frame 79 & -2.37 & 2.33E-04 \\
\hline A_23_P352266 & NM_000633 & $B C L 2$ & B-cell CLL/lymphoma 2 & -2.36 & $1.26 \mathrm{E}-04$ \\
\hline A_23_P207699 & NM_016835 & $M A P T$ & Microtubule-associated protein tau & -2.36 & $1.26 \mathrm{E}-04$ \\
\hline A_23_P392529 & NR_027270 & C21orf81 & $\begin{array}{l}\text { Ankyrin repeat domain } 20 \text { family, member A3 } \\
\text { pseudogene }\end{array}$ & -2.36 & $1.26 \mathrm{E}-04$ \\
\hline A_23_P904 & NM_024603 & BEND5 & BEN domain containing 5 & -2.36 & $1.26 \mathrm{E}-04$ \\
\hline A_23_P115785 & NM_145235 & FANK1 & $\begin{array}{l}\text { Fibronectin type III and ankyrin repeat } \\
\text { domains } 1\end{array}$ & -2.35 & $1.26 \mathrm{E}-04$ \\
\hline A_32_P146844 & N/A & N/A & & -2.35 & $1.26 \mathrm{E}-04$ \\
\hline A_23_P26865 & NM_002470 & МYH3 & $\begin{array}{l}\text { Myosin, heavy chain } 3 \text {, skeletal muscle, } \\
\text { embryonic }\end{array}$ & -2.35 & $1.26 \mathrm{E}-04$ \\
\hline A_32_P100641 & XM_001714998 & LOC 100128139 & Hypothetical LOC100128139 & -2.35 & 2.33E-04 \\
\hline A_24_P930727 & AK091677 & $\mathrm{N} / \mathrm{A}$ & & -2.35 & $1.26 \mathrm{E}-04$ \\
\hline A_23_P406341 & NM_001001936 & AFAP1L2 & Actin filament associated protein 1-like 2 & -2.35 & $1.26 \mathrm{E}-04$ \\
\hline A_24_P54863 & NM_152400 & C4orf32 & Chromosome 4 open reading frame 32 & -2.34 & $1.26 \mathrm{E}-04$ \\
\hline A_23_P133120 & NM_018342 & TMEM144 & Transmembrane protein 144 & -2.34 & $1.26 \mathrm{E}-04$ \\
\hline A_32_P86705 & ВC040577 & $\mathrm{N} / \mathrm{A}$ & & -2.34 & $1.26 \mathrm{E}-04$ \\
\hline A_24_P833256 & N/A & N/A & & -2.33 & $1.26 \mathrm{E}-04$ \\
\hline A_23_P401106 & NM_002599 & $P D E 2 A$ & Phosphodiesterase 2A, cGMP-stimulated & -2.33 & $1.26 \mathrm{E}-04$ \\
\hline A_24_P102119 & AF264623 & N/A & & -2.33 & $1.26 \mathrm{E}-04$ \\
\hline A_23_P358714 & NM_020775 & KIAA1324 & KIAA1324 & -2.32 & $1.26 \mathrm{E}-04$ \\
\hline A_32_P162494 & N/A & N/A & & -2.32 & 3.41E-04 \\
\hline A_23_P326931 & NM_145170 & TTC18 & Tetratricopeptide repeat domain 18 & -2.32 & $1.26 \mathrm{E}-04$ \\
\hline
\end{tabular}

N/A, not annotated; P-value, Benjamini-Hochberg false discovery rate of random permutation test; log fold change, between groups. Gene symbol, accession number and gene name were exported from GeneSpring (from the NCBI databases).

showing significant knockdown effects. FACS analysis revealed that depleting ASPM caused a cell cycle arrest at the
G2/M phase in HCC1937 cells (siEGFP:siASPM, 24.4:34.0\%) at 2 days after transfection, and a subsequent increase in the 
Table IV. Genes specifically expressed in TNBC, but not expressed in normal human vital organs.

\begin{tabular}{|c|c|c|c|c|c|}
\hline Probe ID & Accession no. & Symbol & Gene name & $\begin{array}{l}\text { Fold change } \\
\qquad(\log )\end{array}$ & P-value \\
\hline A_23_P118834 & NM_001067 & TOP2A & Topoisomerase (DNA) II $\alpha 170 \mathrm{kDa}$ & 4.76 & $1.26 \mathrm{E}-04$ \\
\hline A_32_P119154 & BE138567 & $\mathrm{N} / \mathrm{A}$ & & 4.75 & $1.26 \mathrm{E}-04$ \\
\hline A_23_P35219 & NM_002497 & NEK2 & NIMA (never in mitosis gene a)-related kinase 2 & 4.67 & $1.26 \mathrm{E}-04$ \\
\hline A_23_P166360 & NM_206956 & PRAME & Preferentially expressed antigen in melanoma & 4.64 & $1.26 \mathrm{E}-04$ \\
\hline A_24_P332314 & NM_198947 & $F A M 111 B$ & Family with sequence similarity 111 , member B & 4.63 & $1.26 \mathrm{E}-04$ \\
\hline A_24_P413884 & NM_001809 & CENPA & Centromere protein A & 4.59 & $1.26 \mathrm{E}-04$ \\
\hline A_23_P68610 & NM_012112 & $T P X 2$ & $\begin{array}{l}\text { TPX2, microtubule-associated, homolog } \\
\text { (Xenopus laevis) }\end{array}$ & 4.58 & $1.26 \mathrm{E}-04$ \\
\hline A_23_P401 & NM_016343 & CENPF & Centromere protein F, 350/400 ka (mitosin) & 4.44 & $1.26 \mathrm{E}-04$ \\
\hline A_23_P57379 & NM_003504 & $C D C 45 L$ & CDC45 cell division cycle 45-like (S. cerevisiae) & 4.44 & $1.26 \mathrm{E}-04$ \\
\hline A_23_P356684 & NM_018685 & $A N L N$ & Anillin, actin binding protein & 4.29 & $1.26 \mathrm{E}-04$ \\
\hline A_23_P52017 & NM_018136 & $A S P M$ & $\begin{array}{l}\text { asp (abnormal spindle) homolog, microcephaly } \\
\text { associated (Drosophila) }\end{array}$ & 4.17 & $1.26 \mathrm{E}-04$ \\
\hline A_32_P199884 & NM_032132 & HORMADI & HORMA domain containing 1 & 4.13 & 2.33E-04 \\
\hline A_23_P259586 & NM_003318 & $T T K$ & TTK protein kinase & 4.09 & $1.26 \mathrm{E}-04$ \\
\hline A_23_P200310 & NM_017779 & $D E P D C 1$ & DEP domain containing 1 & 4.08 & $1.26 \mathrm{E}-04$ \\
\hline A_23_P115872 & NM_018131 & CEP55 & Centrosomal protein $55 \mathrm{kDa}$ & 4.03 & $1.26 \mathrm{E}-04$ \\
\hline A_24_P911179 & NM_018136 & $A S P M$ & $\begin{array}{l}\text { asp (abnormal spindle) homolog, microcephaly } \\
\text { associated (Drosophila) }\end{array}$ & 4.02 & $1.26 \mathrm{E}-04$ \\
\hline A_24_P96780 & NM_016343 & CENPF & Centromere protein F, 350/400 ka (mitosin) & 3.92 & $1.26 \mathrm{E}-04$ \\
\hline A_24_P14156 & NM_006101 & NDC80 & $\begin{array}{l}\text { NDC80 homolog, kinetochore complex } \\
\text { component (S. cerevisiae) }\end{array}$ & 3.86 & $1.26 \mathrm{E}-04$ \\
\hline A_23_P254733 & NM_024629 & $M L F 1 I P$ & MLF1 interacting protein & 3.85 & $1.26 \mathrm{E}-04$ \\
\hline A_23_P74115 & NM_003579 & $R A D 54 L$ & RAD54-like (S. cerevisiae) & 3.84 & $1.26 \mathrm{E}-04$ \\
\hline A_23_P50108 & NM_006101 & NDC80 & $\begin{array}{l}\text { NDC80 homolog, kinetochore complex } \\
\text { component (S. cerevisiae) }\end{array}$ & 3.84 & $1.26 \mathrm{E}-04$ \\
\hline A_23_P155815 & NM_022346 & $N C A P G$ & Non-SMC condensin I complex, subunit G & 3.82 & $1.26 \mathrm{E}-04$ \\
\hline A_23_P51085 & NM_020675 & $S P C 25$ & $\begin{array}{l}\text { SPC25, NDC } 80 \text { kinetochore complex component, } \\
\text { homolog (S.cerevisiae) }\end{array}$ & 3.81 & $1.26 \mathrm{E}-04$ \\
\hline A_32_P62997 & NM_018492 & $P B K$ & PDZ binding kinase & 3.8 & $1.26 \mathrm{E}-04$ \\
\hline A_23_P256956 & NM_005733 & KIF $20 A$ & Kinesin family member $20 \mathrm{~A}$ & 3.79 & $1.26 \mathrm{E}-04$ \\
\hline A_23_P212844 & NM_006342 & TACC3 & $\begin{array}{l}\text { Transforming, acidic coiled-coil containing } \\
\text { protein } 3\end{array}$ & 3.78 & $1.26 \mathrm{E}-04$ \\
\hline A_24_P254705 & NM_020394 & ZNF695 & Zinc finger protein 695 & 3.76 & $1.26 \mathrm{E}-04$ \\
\hline A_23_P432352 & NM_001017978 & CXorf61 & Chromosome $\mathrm{X}$ open reading frame 61 & 3.73 & $1.26 \mathrm{E}-04$ \\
\hline A_23_P48669 & NM_005192 & $C D K N 3$ & Cyclin-dependent kinase inhibitor 3 & 3.71 & $1.26 \mathrm{E}-04$ \\
\hline A_23_P94571 & NM_004432 & ELAVL2 & $\begin{array}{l}\text { ELAV (embryonic lethal, abnormal vision, } \\
\text { Drosophila)-like } 2 \text { (Hu antigen B) }\end{array}$ & 3.67 & $1.26 \mathrm{E}-04$ \\
\hline A_23_P150667 & NM_031217 & $K I F 18 A$ & Kinesin family member $18 \mathrm{~A}$ & 3.64 & $1.26 \mathrm{E}-04$ \\
\hline A_32_P68525 & ВC035392 & N/A & & 3.58 & $1.26 \mathrm{E}-04$ \\
\hline A_24_P319613 & NM_002497 & $N E K 2$ & NIMA (never in mitosis gene a)-related kinase 2 & 3.53 & $1.26 \mathrm{E}-04$ \\
\hline A_23_P10385 & NM_016448 & $D T L$ & Denticleless homolog (Drosophila) & 3.53 & $1.26 \mathrm{E}-04$ \\
\hline A_23_P94422 & NM_014791 & $M E L K$ & Maternal embryonic leucine zipper kinase & 3.5 & $1.26 \mathrm{E}-04$ \\
\hline A_23_P340909 & $\mathrm{BC} 013418$ & $S K A 3$ & $\begin{array}{l}\text { Spindle and kinetochore associated complex } \\
\text { subunit } 3\end{array}$ & 3.48 & $1.26 \mathrm{E}-04$ \\
\hline A_23_P124417 & NM_004336 & $B U B 1$ & $\begin{array}{l}\text { Budding uninhibited by benzimidazoles } 1 \\
\text { homolog (yeast) }\end{array}$ & 3.47 & $1.26 \mathrm{E}-04$ \\
\hline A_24_P257099 & NM_018410 & HJURP & Holliday junction recognition protein & 3.43 & $1.26 \mathrm{E}-04$ \\
\hline
\end{tabular}


Table IV. Continued.

Probe ID Accession no. Symbol Gene nam

Fold change P-value $(\log )$

\section{A_23_P74349 NM_145697 NUF2}

A_24_P302584 NM_003108

A_24_P68088 NR_002947

A_24_P366033 NM_018098

A_23_P93258 NM_003537

A_23_P149668 NM_014875

A_23_P34325 NM_033300

A_32_P56154 N/A

A_23_P138507 NM_001786

A_23_P49972 NM_001254

A_24_P306896 XR_040656

A_23_P44684 NM_018098

A_23_P100344 NM_014321

A_23_P163481 NM_001211

A_32_P87849 N/A

A_24_P397107 NM_001789

A_23_P209200 NM_001238

A_32_P16625 N/A

A_24_P37903 N/A

A_24_P313504 NM_005030

A_23_P252292 NM_006733

A_23_P161474 NM_182751

A_23_P253762 N/A

A_24_P225534 NM_017821

A_24_P412088 NM_182751

A_32_P109296 NM_152259

A_24_P76521 AK056691

A_23_P126212 NM_022111

A_23_P60120 NM_031415

A_24_P902509 NM_018193

A_23_P155969 NM_014264

A_32_P183218 NM_153695

A_23_P46118 NM_001821

A_23_P327643 N/A

A_23_P215976 NM_057749

A_32_P151800 NM_207418

A_23_P34788 NM_006845

A_23_P133956 NM_002263

A_23_P88630 NM_000057

A_24_P276102 NM_183404

A_23_P23303 NM_003686

A_23_P88691 NM_000745

A_32_P72341 NM_173084
SOX 11

TCAM1

ECT2

HIST1H3B

KIF 14

LRP

$\mathrm{N} / \mathrm{A}$

$C D C 2$

CDC6

LOC283711

ECT2

ORC6L

$B U B 1 B$

$\mathrm{N} / \mathrm{A}$

CDC25A

CCNE1

N/A

LOX

PLK 1

CENPI

MCM10

N/A

RHBDL2

MCM10

C15orf42

GSG2

CLSPN

GSDMC

FANCI

PLK4

ZNF367

CHML

N/A

CCNE2

FAM72D

KIF $2 C$

KIFC1

BLM

RBLI

EXO1

CHRNA5

TRIM59
NUF2, NDC80 kinetochore complex component, homolog (S. cerevisiae)

\section{SRY (sex determining region Y)-box 11}

Testicular cell adhesion molecule 1 homolog (mouse)

Epithelial cell transforming sequence 2 oncogene

Histone cluster 1, H3b

Kinesin family member 14

Low density lipoprotein receptor-related protein 8, apolipoprotein E receptor

Cell division cycle $2, \mathrm{G} 1 \rightarrow \mathrm{S}$ and $\mathrm{G} 2 \rightarrow \mathrm{M}$

Cell division cycle 6 homolog (S. cerevisiae)

Hypothetical protein LOC283711

Epithelial cell transforming sequence 2 oncogene

Origin recognition complex, subunit 6 like (yeast)

Budding uninhibited by benzimidazoles 1

homolog $\beta$ (yeast)

Cell division cycle 25 homolog A (S. pombe)

Cyclin E1

Lysyl oxidase

Polo-like kinase 1 (Drosophila)

Centromere protein I

Minichromosome maintenance complex

component 10

Rhomboid, veinlet-like 2 (Drosophila)

Minichromosome maintenance complex component 10

Chromosome 15 open reading frame 42

Germ cell associated 2 (haspin)

Claspin homolog (Xenopus laevis)

Gasdermin C

Fanconi anemia, complementation group I

Polo-like kinase 4 (Drosophila)

Zinc finger protein 367

Choroideremia-like (Rab escort protein 2)

Cyclin E2

Family with sequence similarity 72, member D

Kinesin family member $2 \mathrm{C}$

Kinesin family member $\mathrm{C} 1$

Bloom syndrome, RecQ helicase-like

Retinoblastoma-like 1 (p107)

Exonuclease 1

Cholinergic receptor, nicotinic, $\alpha 5$

Tripartite motif-containing 59
3.36

$1.26 \mathrm{E}-04$

3.36

3.35

3.34

3.33

3.29

3.28

3.28

3.24

3.22

3.22

3.21

3.2

3.17

3.16

3.15

3.15

3.15

3.12

3.07

3.04

2.99

2.94

2.94

2.94

2.91

2.83

2.83

2.81

2.8

2.79

2.77

2.76

2.75

2.72

2.7

2.7

2.69

2.68

2.68

2.67

2.67

2.62
4.43E-04

2.33E-04

$1.26 \mathrm{E}-04$

1.26E-04

1.26E-04

$1.26 \mathrm{E}-04$

1.26E-04

$1.26 \mathrm{E}-04$

$1.26 \mathrm{E}-04$

$1.26 \mathrm{E}-04$

1.26E-04

$1.26 \mathrm{E}-04$

$1.26 \mathrm{E}-04$

1.26E-04

$1.26 \mathrm{E}-04$

$1.26 \mathrm{E}-04$

$1.26 \mathrm{E}-04$

$1.26 \mathrm{E}-04$

1.26E-04

1.26E-04

$1.26 \mathrm{E}-04$

$1.26 \mathrm{E}-04$

$1.26 \mathrm{E}-04$

$1.26 \mathrm{E}-04$

$1.26 \mathrm{E}-04$

$1.26 \mathrm{E}-04$

$1.26 \mathrm{E}-04$

2.33E-04

$1.26 \mathrm{E}-04$

$1.26 \mathrm{E}-04$

$1.26 \mathrm{E}-04$

2.33E-04

1.26E-04

2.33E-04

1.26E-04

$1.26 \mathrm{E}-04$

$1.26 \mathrm{E}-04$

$1.26 \mathrm{E}-04$

1.26E-04

1.26E-04

$1.26 \mathrm{E}-04$

$1.26 \mathrm{E}-04$ 
Table IV. Continued.

\begin{tabular}{|c|c|c|c|c|c|}
\hline Probe ID & Accession no. & Symbol & Gene name & $\begin{array}{l}\text { Fold change } \\
\qquad(\log )\end{array}$ & P-value \\
\hline A_24_P227091 & NM_004523 & KIF11 & Kinesin family member 11 & 2.61 & $1.26 \mathrm{E}-04$ \\
\hline A_23_P136805 & NM_014783 & ARHGAP11A & Rho GTPase activating protein $11 \mathrm{~A}$ & 2.6 & $1.26 \mathrm{E}-04$ \\
\hline A_23_P63402 & NM_013296 & GPSM2 & $\begin{array}{l}\text { G-protein signaling modulator } 2 \text { (AGS3-like, } \\
\text { C. elegans) }\end{array}$ & 2.6 & $1.26 \mathrm{E}-04$ \\
\hline A_23_P35871 & NM_024680 & $E 2 F 8$ & E2F transcription factor 8 & 2.58 & $1.26 \mathrm{E}-04$ \\
\hline A_23_P207307 & N/A & N/A & & 2.58 & $1.26 \mathrm{E}-04$ \\
\hline A_24_P399888 & NM_001002876 & CENPM & Centromere protein $\mathrm{M}$ & 2.58 & $1.26 \mathrm{E}-04$ \\
\hline A_23_P155989 & NM_022145 & CENPK & Centromere protein $\mathrm{K}$ & 2.57 & $1.26 \mathrm{E}-04$ \\
\hline A_23_P411335 & NM_152524 & SGOL2 & Shugoshin-like 2 (S. pombe) & 2.54 & $1.26 \mathrm{E}-04$ \\
\hline A_23_P43484 & NM_058197 & $C D K N 2 \mathrm{~A}$ & $\begin{array}{l}\text { Cyclin-dependent kinase inhibitor 2A } \\
\text { (melanoma, p16, inhibits CDK4) }\end{array}$ & 2.52 & $1.26 \mathrm{E}-04$ \\
\hline A_32_P28704 & N/A & N/A & & 2.52 & $1.26 \mathrm{E}-04$ \\
\hline A_24_P351466 & NM_020890 & KIAA1524 & KIAA1524 & 2.5 & $1.26 \mathrm{E}-04$ \\
\hline A_24_P334248 & NM_014996 & PLCH1 & Phospholipase C, eta 1 & 2.48 & $1.26 \mathrm{E}-04$ \\
\hline A_23_P88331 & NM_014750 & $D L G A P 5$ & $\begin{array}{l}\text { Discs, large (Drosophila) homolog-associated } \\
\text { protein } 5\end{array}$ & 2.47 & $1.26 \mathrm{E}-04$ \\
\hline A_32_P31021 & N/A & $\mathrm{N} / \mathrm{A}$ & & 2.46 & $1.26 \mathrm{E}-04$ \\
\hline A_23_P361419 & NM_018369 & $D E P D C 1 B$ & DEP domain containing $1 \mathrm{~B}$ & 2.45 & $1.26 \mathrm{E}-04$ \\
\hline A_23_P397341 & NM_152341 & PAQR4 & Progestin and adipoQ receptor family member IV & 2.42 & $1.26 \mathrm{E}-04$ \\
\hline A_23_P140316 & NM_001099652 & GPR137C & G protein-coupled receptor $137 \mathrm{C}$ & 2.42 & $1.26 \mathrm{E}-04$ \\
\hline A_23_P217049 & NM_014286 & FREQ & Frequenin homolog (Drosophila) & 2.41 & $2.33 \mathrm{E}-04$ \\
\hline A_32_P35839 & N/A & $\mathrm{N} / \mathrm{A}$ & & 2.4 & $1.26 \mathrm{E}-04$ \\
\hline A_24_P857404 & NM_001093725 & $M E X 3 A$ & mex-3 homolog A (C. elegans) & 2.4 & $1.26 \mathrm{E}-04$ \\
\hline A_24_P323598 & NM_001017420 & ESCO2 & $\begin{array}{l}\text { Establishment of cohesion } 1 \text { homolog } 2 \\
\text { (S. cerevisiae) }\end{array}$ & 2.36 & $1.26 \mathrm{E}-04$ \\
\hline A_23_P112673 & NM_017975 & ZWILCH & $\begin{array}{l}\text { Zwilch, kinetochore associated, homolog } \\
\text { (Drosophila) }\end{array}$ & 2.33 & $1.26 \mathrm{E}-04$ \\
\hline A_24_P296254 & NM_014783 & ARHGAP11A & Rho GTPase activating protein 11A & 2.32 & $1.26 \mathrm{E}-04$ \\
\hline
\end{tabular}

N/A, not annotated; P-value, Benjamini-Hochberg false discovery rate of random permutation test; log fold change, between groups. Gene symbol, accession number and gene name were exported from GeneSpring (from the NCBI databases).

sub-G1 population (siEGFP:siASPM, 9.86:43.68\%) at 6 days (Fig. 5A). On the other hand, reduced CENPK expression resulted in an increase in the proportion of $\mathrm{G} 0 / \mathrm{G} 1$ phase cells (siEGFP:siCENPK, 56.49:72.2\%) in MDA-MB-231 after 2 days of transfection, and a subsequent increase in the sub-G1 population (siEGFP:siCENPK, 12.73:30.96\%) at 6 days (Fig. 5B). Interestingly, we observed an enlarged size of HCC1937 cells, which was likely due to abnormal tubulin formation due to decreased ASPM expression (Fig. 5C, arrowheads). In addition, we observed a disruption in the structural integrity of tubulin in $C E N P K$-depleted MDA-MB-231 cells (Fig. 5D, arrowheads), compared with those in siEGFPtransfected cells.

These results suggest that the absence of $A S P M$ and $C E N P K$ caused an arrest in the G2/M and G0/G1 phases, respectively, and then induced cell death. Taken together, these findings strongly suggest that $A S P M$ and $C E N P K$ have indispensable roles in cell proliferation and mitosis, especially in the $\mathrm{G} 2 / \mathrm{M}$ and G0/G1 phases, in TNBC cells.

\section{Discussion}

TNBC patients do not benefit from endocrine therapy and trastuzumab. Conventional chemotherapy is currently the mainstay of systemic medical treatment, although TNBC patients have a worse outcome after chemotherapy than patients with other breast subtypes. In particular, because cytotoxic drugs often cause severe adverse effects, it is obvious that thoughtful selection of novel target molecules based on the detailed molecular mechanisms of TNBC carcinogenesis 
Table V. Genes listed in cluster 1 and cluster 2.

No. of genes

Genes

Cluster 1 (enrichment score, 29.90) 87

BLM, CKS1B, CKS2, CHEK1, E2F1, E2F2, E2F8, FANCA, FANCI, H2AFX, HORMAD1, HJURP, MAD2L1, NDC80, NEK2, NUF2, OIP5, PBK, RAD51, RAD54L, SPC25, TPX2, TTK, ZWINT ZWILCH, ANLN, ASPM, AURKA, BIRC5, BUB1, BUB1B, CASC5, CDC25A, CDC6, CDCA2, CDCA5, CDCA8, CENPA, CENPF, CEP55, CHAF1B, SKA3, C13orf34, CIT, CLSPN, CCNA2, CCNB1, CCNE1, CCNE2, CDKN2A, CDKN2C, CDKN3, DSCC1, DLGAP5, ESCO2, EXO1, FAM83D, GSG2, INHBA, KIF11, KIF 14, KIF 18A, KIF18B, KIF20A, KIF23, KIF2C, KIFC1, LMNB1, MND1, NCAPG, NUSAP1, PTTG1, PLK1, PLK4, PKMYT1, PRC1, RBL1, SGOL2 SPAG5, STMN1, SMC4, TMSB15A, TOP2A, TACC3, TUBB3, UBE2C, UHRF1

Cluster 2 (enrichment score, 6.43) 45

ADAMTS5, MAMDC2, SPARCL1, WIF1, AZGP1, APOD, FIGF, CHL1, CCL28, CXCL2, COLAA6, COL14A1, COL17A1, CNTNAP3, DKK3, DST, FGF1, FMOD, HS3ST4, IGJ, IL33, LAMA3, LAMAB, LTBP2, LIFR, LRP2, MASP2, MATN2, MGP, NTN4, NRG1, PTHLH, PI15, PLAT, PDGFA, PTN, PIGR, PIP, SCGB1D1, SCGB1D2, SCGB3A1, SEMA3G, STC2, THSD4, TFF3

Genes enriched in cluster 1 and cluster 2 according to DAVID.

Cluster 1

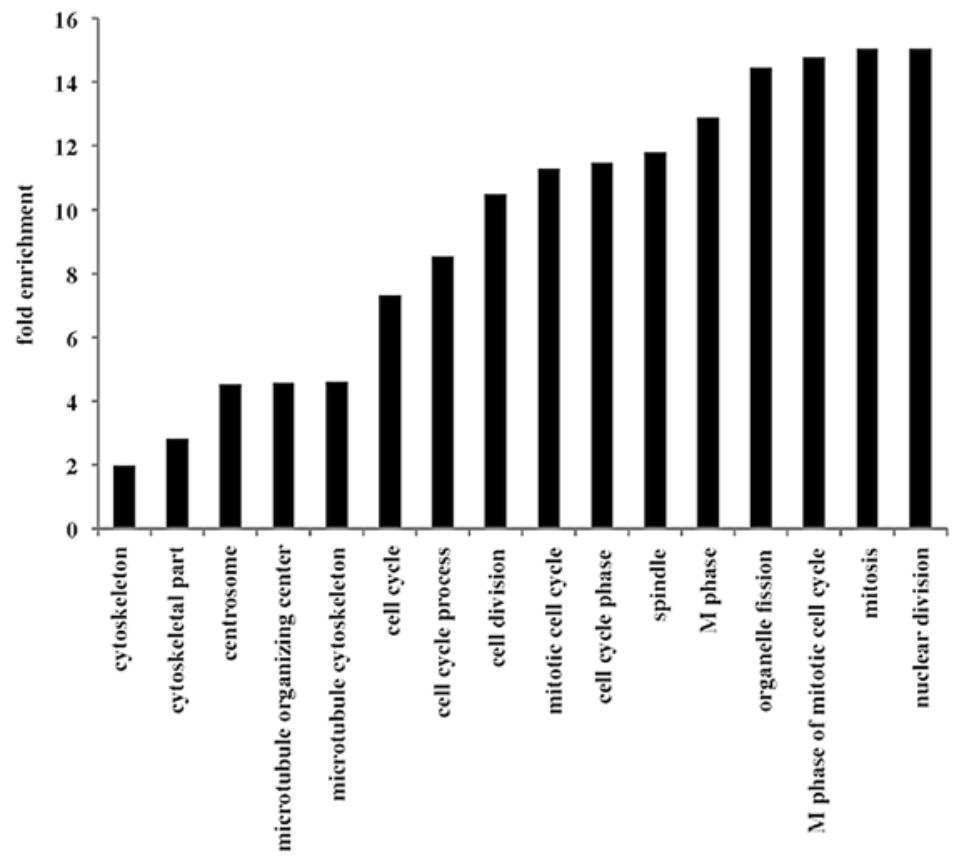

Cluster 2

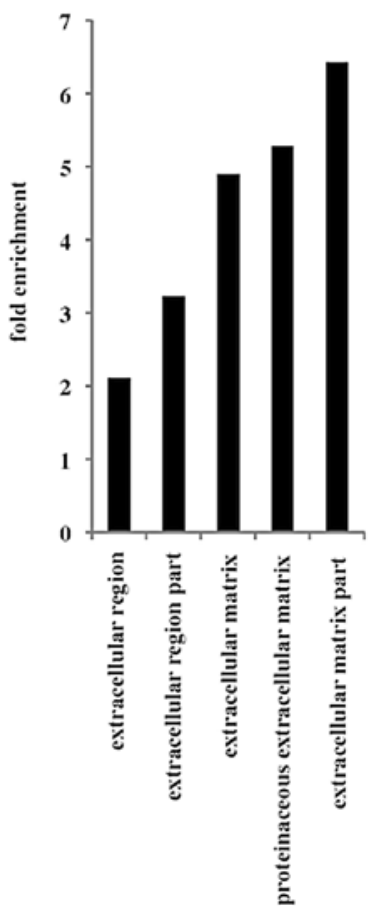

Figure 2. Gene annotation enrichment analysis based on DAVID was performed to elucidate the biological processes and pathways characterized in TNBC. Functional annotation terms are shown in bar plots; the value of the vertical axis represents the fold enrichment score of each term.

should be very helpful to develop effective anticancer drugs with a minimum risk of side effects. To this end, we performed
DNA microarray using the microdissected TNBC and normal ductal cells, and normal human vital organs including the 


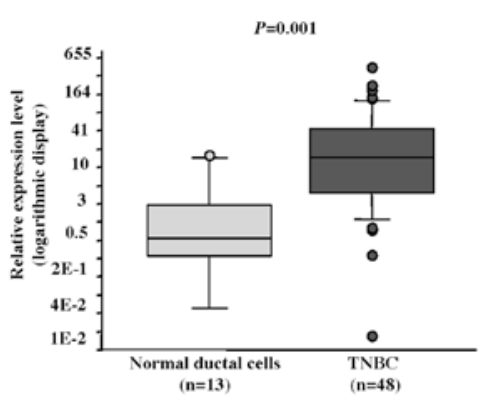

CENPK

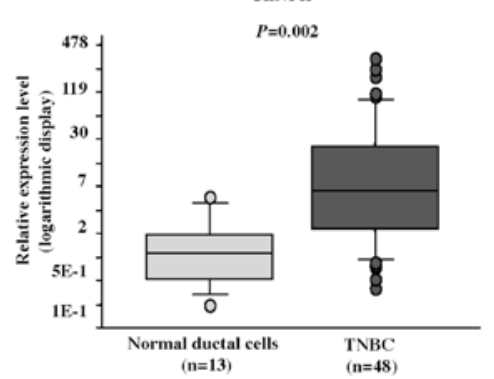

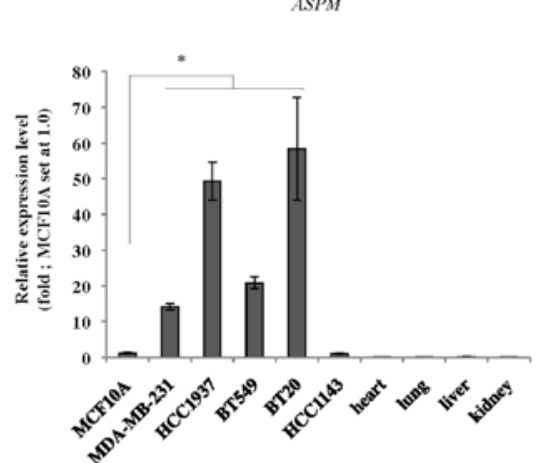

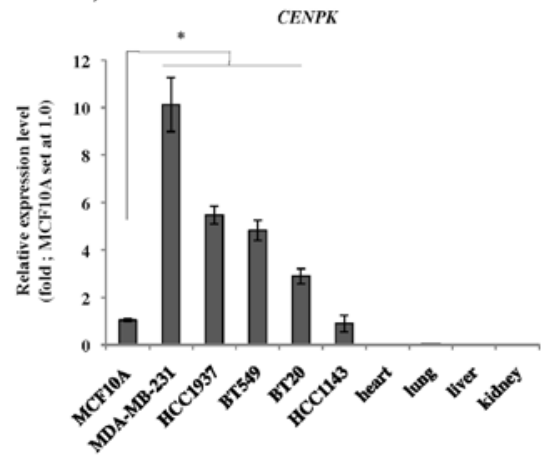

Figure 3. ASPM and CENPK expression profiles. (A) qRT-PCR results of $A S P M$ and $C E N P K$ in microdissected tumor cells from 48 TNBC tissues and 13 normal ductal cells (Mann-Whitney t-test). (B) qRT-PCR results of ASPM and CENPK in five TNBC cell lines, MCF10A cells (human normal mammary epithelial cell line) and various normal organs (Student's two-sided t-test: "P<0.05).

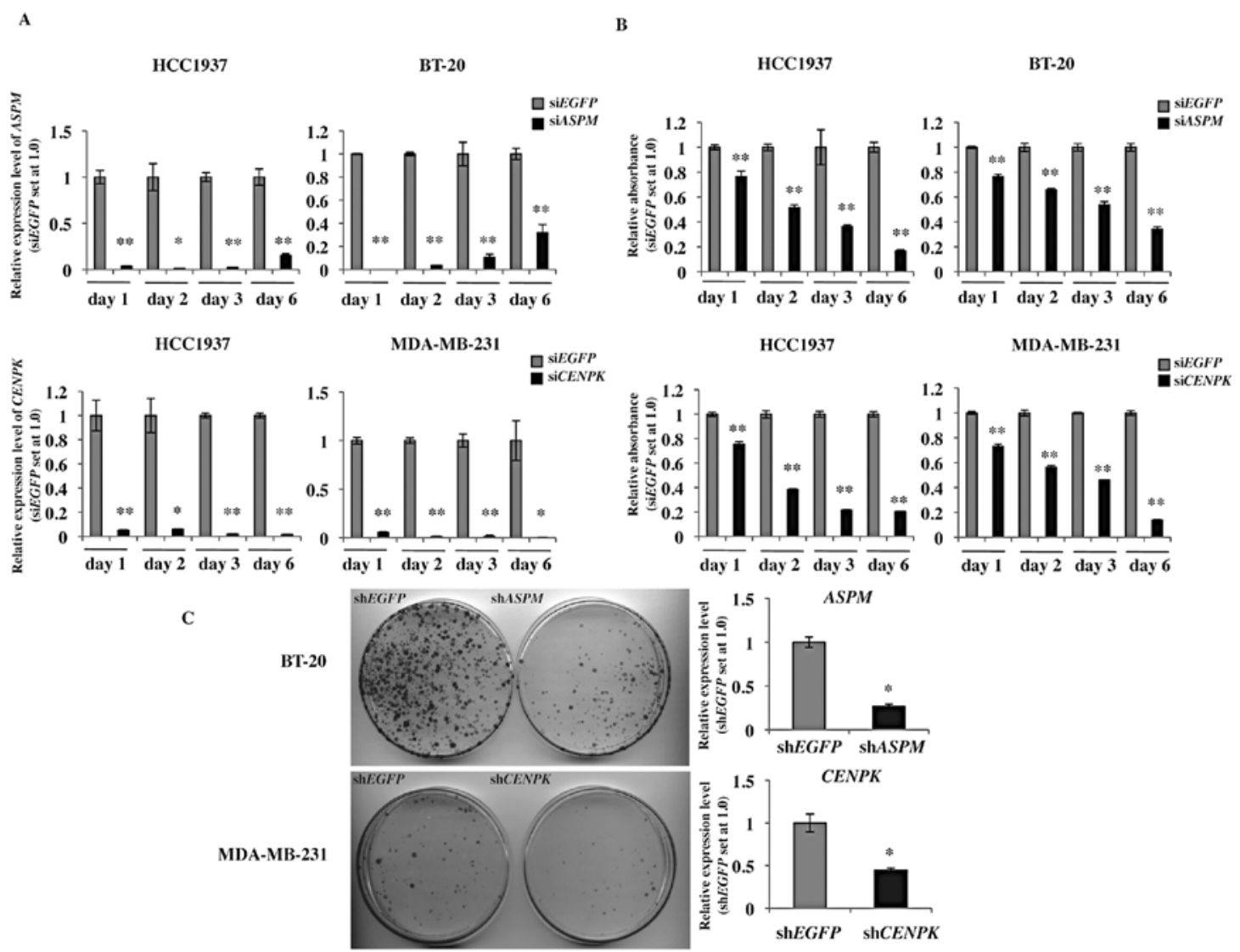

Figure 4. siRNA-mediated growth inhibitory effects in TNBC cells. (A) siRNA-mediated knockdown of ASPM in HCC1937 and BT-20 cells, and CENPK in HCC1937 and MDA-MB-231 cells was validated by qRT-PCR analysis (Student's two-sided t-test: ${ }^{*} \mathrm{P}<0.05,{ }^{* * *} \mathrm{P}<0.01$ ). (B) The MTT assay showing a decrease in the number of cells upon ASPM knockdown in HCC1937 and BT-20 cells and CENPK knockdown in HCC1937 and MDA-MB-231 cells (Student's two-sided t-test: ${ }^{*} \mathrm{P}<0.05,{ }^{* *} \mathrm{P}<0.01$ ). (C) Colony formation assay (left) demonstrating a decrease in the number of colonies upon ASPM and CENPK knockdown (right) (Student's two-sided t-test: "P<0.05). 
A

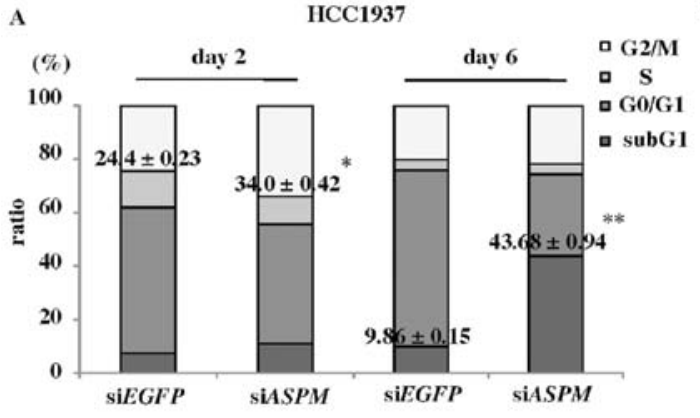

C
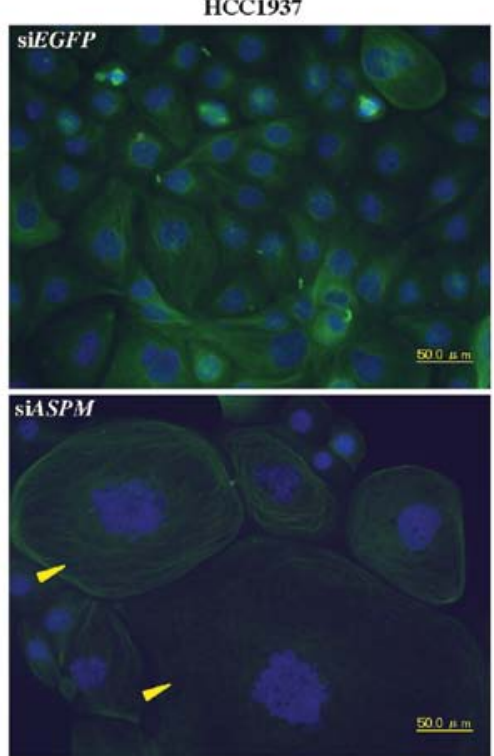

B

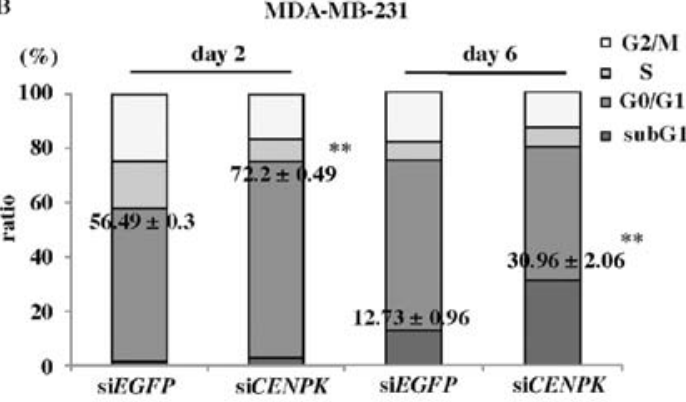

D
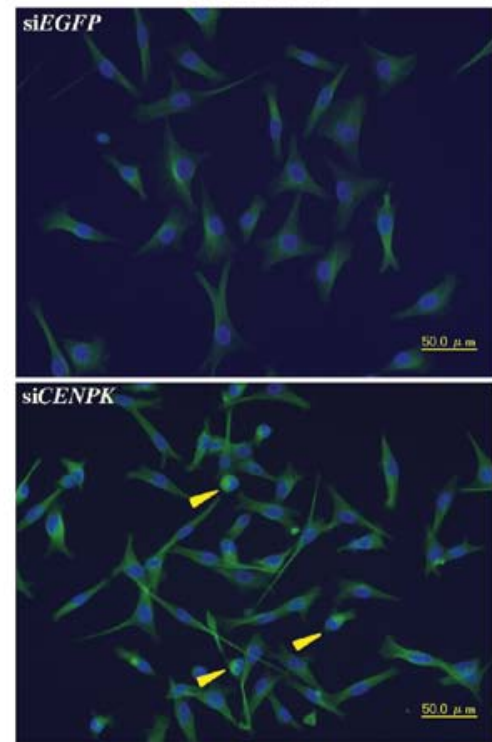

Figure 5. Alteration of the cell cycle and changes in cancer cell morphology upon ASPM and CENPK knockdown in TNBC cells. (A) FACS analysis at each time-point. The proportion of cells at the G2/M phase was elevated 2 days after siASPM transfection followed by sub-G1 induction at 6 days in HCC1937 cells. (B) Upon CENPK knockdown, the proportion of cells at the G0/G1 phase was elevated in MDA-MB-231 cells at 2 days after siCENPK transfection, followed by sub-G1 induction at 6 days after transfection. A total of 10,000 cells were counted (Student's two-sided t-test: $\left.{ }^{*} \mathrm{P}<0.05,{ }^{* * *} \mathrm{P}<0.01\right)$. (C) Immunocytochemical staining analysis of $\alpha / \beta$-tubulin at $48 \mathrm{~h}$ after siRNA transfection. Enlarged siASPM-treated HCC1937 cells (arrowhead). Control cells that entered metaphase are indicated by the arrow. (D) Disruption of the structural integrity of tubulin in siCENPK-treated MDA-MB-231 cells (arrowhead). $\alpha / \beta$-tubulin and nuclei staining are shown as green and blue, respectively. Scale bars, $50 \mu \mathrm{m}$.

heart, lung, liver and kidney and identified 104 genes that were significantly upregulated in TNBC compared to normal duct cells, but not expressed in normal human vital organs. They included cancer specific kinases, such as $N E K 2, P B K$, and $M E L K$, which might serve as druggable targets for new therapeutic agents against TNBC.

$N E K 2$, a member of the NIMA-related serine/threonine kinase family, is involved in cell division and the mitotic regulation by centrosome splitting, and is upregulated in a wide variety of human cancers including breast cancer (40). siRNA-mediated depletion of $N E K 2$ expression results in growth suppression of breast and colorectal cancers $(29,30) . P B K$, a mitotic serine/ threonine kinase, is significantly upregulated in the majority of breast cancers. siRNA-mediated knockdown of PBK expression also results in significant suppression of cell growth due to cytokinetic failure (31). MELK, a member of the snf1/AMPK serine-threonine kinase family, is involved in mammalian embryonic development and is also frequently upregulated in breast cancers and brain tumors $(33,41)$. Suppression of $M E L K$ expression by siRNA significantly inhibits the growth of human breast cancer cells (33). These findings strongly suggest that these cancer-specific kinases, $N E K 2, P B K$ and $M E L K$, are promising therapeutic targets for TNBC.

Furthermore, we performed a gene-annotation enrichment analysis using DAVID based on gene expression profiling to elucidate the biological processes and pathways associated with each gene cluster. We found that the vast majority of genes upregulated in TNBC are functionally responsible for cell cycle progression involved in nuclear division, microtubule organization, kinetochore, and chromosome segregation, and that most inactivated functions closely related to TNBC progression are involved in cell-cell or cell-matrix interactions, which is consistent with epithelial mesenchymal transition (EMT) features as a phenotype of TNBC (42).

To further the development of novel anticancer drugs with minimum adverse effects, we focused on the cancerspecific cell-cycle associated genes $A S P M$ and $C E P N K$ as novel molecular targets for TNBC therapy. ASPM has been reported to play an essential role in nucleating microtubules at centrosomes, to localize to the spindle poles during mitosis (39) and to contribute to glioblastoma cell growth (43), but has not been associated with breast carcinogenesis, especially 
TNBC. Here, we confirmed that $A S P M$ is upregulated in clinical samples and TNBC cell lines (Fig. 3) and that siRNAmediated knockdown of endogenous $A S P M$ results in the loss of nucleating microtubules through mitosis by impeding centrosome function, resulting in $\mathrm{G} 2 / \mathrm{M}$ cell cycle arrest and subsequent apoptosis. These results suggest that aberrant $A S P M$ expression might be involved in the carcinogenesis of TNBC and that $A S P M$ targeting might be an attractive therapeutic option with less adverse effects. $C E N P K$ is known to be a subunit of the CENPH-I complex, and essential for proper kinetochore assembly (39), but little is known about the roles of $C E N P K$ in human cancer growth, progression, and carcinogenesis. We also confirmed that $C E N P K$ is upregulated in clinical samples and TNBC cell lines, and that siRNA-mediated knockdown also causes cell growth inhibition through G0/G1 cell cycle arrest due to a loss of correct tubulin structures (Figs. 3-5). Interestingly, we determined that other centromere or kinetochore-associated proteins, CENPA, CENPF, CENPI, CENPM, NDC80 and HJURP, were also significantly overexpressed in TNBC cases, but not expressed in normal vital organs (Fig. 1C and Table IV). Human CENPA was first identified based on autoantibodies found in patients suffering from scleroderma (44) and is overexpressed in colorectal cancers (45). CENPF is also reportedly upregulated in head and neck squamous cell carcinomas and pancreatic ductal carcinomas $(46,47)$. NDC 80 and HJURP are reportedly overexpressed in breast cancers and associated with tumor grade and poor prognosis $(48,49)$. These findings suggest that aberrant regulation of kinetochore assembly and centromere function through mitosis might contribute to the carcinogenesis of TNBC and that destroying one component of the kinetochore, such as targeting CENPK, might be a novel molecular target for TNBC treatment.

TNBC is a heterogeneous subgroup of breast cancers; therefore oncologists, pathologists, and geneticists had tried to clarify TNBC by means of gene expression profiling and immunohistochemical analyses. We also applied unsupervised 2-dimensional hierarchical clustering analysis to groups of genes based on similarities in the expression pattern, but there is no clustering for TNBC based on gene expression patterns, probably due to the small sample size (data not shown). However, the information provided in this study will facilitate the development of novel and attractive molecular drug targets without adverse events.

\section{Acknowledgements}

We thank Dr Tomoya Fukawa and Dr Le Tan Dat for helpful and constructive discussions and Ms. Hitomi Kawakami for technical assistance in microdissection. This work was supported in part by a grant from Health Labour Research Grant 'Third Term Comprehensive Control Research for Cancer (H24-3rd-Gan-Ippan-006), and Kobayashi Foundation for cancer Research (2009) (TK).

\section{References}

1. Jemal A, Siegel R, Ward E, Hao Y, Xu J, Murray T and Thun MJ: Cancer Statistics, 2008. CA Cancer J Clin 58: 71-96, 2008
2. Di Cosimo S and Baselga J: Management breast cancer with targeted agents: importance of heterogeneity. Nat Rev Clin Oncol 7: 139-147, 2010.

3. Rahman M, Pumphrey JG and Lipkowitz S: The TRAIL to targeted therapy of breast cancer. Adv Cancer Res 103: 43-73, 2009.

4. Smith I, Procter M, Gelber RD, Guillaume S, Feyereislova A, Dowsett M, Goldhirsch A, Untch M, Mariani G, Baselga J, Kaufmann M, Cameron D, Bell R, Bergh J, Coleman R, Wardley A, Harbeck N, Lopez RI, Mallmann P, Gelmon K, Wilcken N, Wist E, Sánchez Rovira P and Piccart-Gebhart MJ: HERA study team: 2-year follow-up of trastuzumab after adjuvant chemotherapy in HER2-positive breast cancer: a randomised controlled trial. Lancet 369: 29-36, 2007.

5. Romond EH, Perez EA, Bryant J, Suman VJ, Geyer CE Jr, Davidson NE, Tan-Chiu E, Martino S, Paik S, Kaufman PA, Swain SM, Pisansky TM, Fehrenbacher L, Kutteh LA, Vogel VG, Visscher DW, Yothers G, Jenkins RB, Brown AM, Dakhil SR, Mamounas EP, Lingle WL, Klein PM, Ingle JN and Wolmark N: Trastuzumab plus adjuvant chemotherapy for operable HER2-positive breast cancer. N Engl J Med 353: 1673-1684, 2005.

6. Joensuu H, Kellokumpu-Lehtinen PL, Bono P, Alanko T, Kataja V, Asola R, Utriainen T, Kokko R, Hemminki A, Tarkkanen M, Turpeenniemi-Hujanen T, Jyrkkiö S, Flander M, Helle L, Ingalsuo S, Johansson K, Jääskeläinen AS, Pajunen M, Rauhala M, Kaleva-Kerola J, Salminen T, Leinonen M, Elomaa I and Isola J, for the FinHer Study Investigators: Adjuvant docetaxel or vinorelbine with or without trastuzumab for breast cancer. N Engl J Med 354: 809-820, 2006.

7. Foulkes WD, Smith IE and Reis-Filho JS: Triple-negative breast cancer. N Engl J Med 363: 1938-1948, 2010.

8. Liedtke C, Mazouni C, Hess KR, André F, Tordai A, Mejia JA, Symmans WF, Gonzalez-Angulo AM, Hennessy B, Green M, Cristofanilli M, Hortobagyi GN and Pusztai L: Response to neoadjuvant therapy and long-term survival in patients with triple-negative breast cancer. J Clin Oncol 26: 1275-1281, 2008.

9. Petricoin EF III, Hackett JL, Lesko LJ, Puri RK, Gutman SI, Chumakov K, Woodcock J, Feigal DW Jr, Zoon KC and Sistare FD: Medical applications of microarray technologies: a regulatory science perspective. Nat Genet 32: 474-479, 2002.

10. Huang DW, Sherman BT and Lempicki RA: Systematic and integrative analysis of large gene lists using DAVID Bioinformatics Resources. Nat Protoc 4: 44-57, 2009.

11. Huang DW, Sherman BT and Lempicki RA: Bioinformatics enrichment tools: paths toward the comprehensive functional analysis of large gene lists. Nucleic Acids Res 37: 1-13, 2009.

12. Hao JM, Chen JZ, Sui HM, Si-Ma XQ, Li GQ, Liu C, Li JL, Ding YQ and Li JM: A five-gene signature as a potential predictor of metastasis and survival in colorectal cancer. J Pathol 220: 475-489, 2010.

13. Ueki T, Park JH, Nishidate T, Kijima K, Hirata K, Nakamura Y and Katagiri T: Ubiquitination and downregulation of BRCA1 by ubiquitin-conjugating enzyme E2T overexpression in human breast cancer cells. Cancer Res 69: 8752-8760, 2009.

14. Loussouarn D, Campion L, Leclair F, Campone M, Charbonnel C, Ricolleau G, Gouraud W, Bataille R and Jézéquel P: Validation of UBE2C protein as a prognostic marker in node-positive breast cancer. Br J Cancer 101: 166-173, 2009.

15. Arumugam T and Logsdon CD: S100P: a novel therapeutic target for cancer. Amino Acids 41: 893-899, 2011.

16. Xiang T, Li L, Yin X, Yuan C, Tan C, Su X, Xiong L, Putti TC, Oberst M, Kelly K, Ren G and Tao Q: The ubiquitin peptidase UCHL1 induces G0/G1 cell cycle arrest and apoptosis through stabilizing p53 and is frequently silenced in breast cancer. PLoS One 7: e29783, 2012.

17. Yoon CH, Kim MJ, Lee H, Kim RK, Lim EJ, Yoo KC, Lee GH, Cui YH, Oh YS, Gye MC, Lee YY, Park IC, An S, Hwang SG, Park MJ, Suh Y and Lee SJ: PTTG1 oncogene promotes tumor malignancy via epithelial to mesenchymal transition and expansion of cancer stem cell population. J Biol Chem 287: 19516-19527, 2012.

18. Jin W, Liu Y, Xu SG, Yin WJ, Li JJ, Yang JM and Shao ZM: UHRF1 inhibits MDR1 gene transcription and sensitizes breast cancer cells to anticancer drugs. Breast Cancer Res Treat 124: 39-48, 2010.

19. Ford HL, Landesman-Bollag E, Dacwag CS, Stukenberg PT, Pardee AB and Seldin DC: Cell cycle-regulated phosphorylation of the human SIX1 homeodomain protein. J Biol Chem 275: 22245-22254, 2000. 
20. Shimo A, Nishidate T, Ohta T, Fukuda M, Nakamura Y and Katagiri T: Elevated expression of protein regulator of cytokinesis 1, involved in the growth of breast cancer cells. Cancer Sci 98: 174-181, 2007

21. Di Leo A and Isola J: Topoisomerase II alpha as a marker predicting the efficacy of anthracyclines in breast cancer: are we at the end of the beginning? Clin Breast Cancer 4: 179-186, 2003.

22. Nakagawa M, Bando Y, Nagao T, Morimoto M, Takai C, Ohnishi T, Honda J, Moriya T, Izumi K, Takahashi M, Sasa M and Tangoku A: Expression of p53, Ki-67, E-cadherin, N-cadherin and TOP2A in triple-negative breast cancer. Anticancer Res 31: 2389-2393, 2011.

23. Adélaïde J, Finetti P, Bekhouche I, Repellini L, Geneix J, Sircoulomb F, Charafe-Jauffret E, Cervera N, Desplans J, Parzy D, Schoenmakers E, Viens P, Jacquemier J, Birnbaum D, Bertucci $\mathrm{F}$ and Chaffanet $\mathrm{M}$ : Integrated profiling of basal and luminal breast cancers. Cancer Res 67: 11565-11575, 2007.

24. Liu RZ, Graham K, Glubrecht DD, Germain DR, Mackey JR and Godbout R: Association of FABP5 expression with poor survival in triple-negative breast cancer: implication for retinoic acid therapy. Am J Pathol 178: 997-1008, 2011.

25. Kalashnikova EV, Revenko AS, Gemo AT, Andrews NP Tepper CG, Zou JX, Cardiff RD, Borowsky AD and Chen HW: ANCCA/ATAD2 overexpression identifies breast cancer patients with poor prognosis, acting to drive proliferation and survival of triple-negative cells through control of B-Myb and EZH2. Cancer Res 70: 9402-9412, 2010.

26. Parris TZ, Danielsson A, Nemes S, Kovács A, Delle U, Fallenius G, Möllerström E, Karlsson P and Helou K: Clinical implications of gene dosage and gene expression patterns in diploid breast carcinoma. Clin Cancer Res 16: 3860-3874, 2010.

27. Ai L, Tao Q, Zhong S, Fields CR, Kim WJ, Lee MW, Cui Y, Brown KD and Robertson KD: Inactivation of Wnt inhibitory factor-1 (WIF1) expression by epigenetic silencing is a common event in breast cancer. Carcinogenesis 27: 1341-1348, 2006.

28. Cheng CJ, Lin YC, Tsai MT, Chen CS, Hsieh MC, Chen CL and Yang RB: SCUBE2 suppresses breast tumor cell proliferation and confers a favorable prognosis in invasive breast cancer. Cancer Res 69: 3634-3641, 2009.

29. Tsunoda N, Kokuryo T, Oda K, Senga T, Yokoyama Y, Nagino M, Nimura Y and Hamaguchi M: Nek2 as a novel molecular target for the treatment of breast carcinoma. Cancer Sci 100: 111-116, 2009.

30. Suzuki K, Kokuryo T, Senga T, Yokoyama Y, Nagino M and Hamaguchi M: Novel combination treatment for colorectal cancer using Nek2 siRNA and cisplatin. Cancer Sci 101: 1163-1169, 2010.

31. Park JH, Lin ML, Nishidate T, Nakamura $Y$ and Katagiri T: PDZ-binding kinase/T-LAK cell-originated protein kinase, a putative cancer/testis antigen with an oncogenic activity in breast cancer. Cancer Res 66: 9186-9195, 2006.

32. Ueki T, Nishidate T, Park JH, Lin ML, Shimo A, Hirata K, Nakamura $Y$ and Katagiri T: Involvement of elevated expression of multiple cell-cycle regulator, DTL/RAMP (denticleless/ RA-regulated nuclear matrix associated protein), in the growth of breast cancer cells. Oncogene 27: 5672-5683, 2008.

33. Lin ML, Park JH, Nishidate T, Nakamura Y and Katagiri T: Involvement of maternal embryonic leucine zipper kinase (MELK) in mammary carcinogenesis through interaction with Bcl-G, a pro-apoptotic member of the Bcl-2 family. Breast Cancer Res 9: R17, 2007.

34. Shimo A, Tanikawa C, Nishidate T, Lin ML, Matsuda K, Park JH, Ueki T, Ohta T, Hirata K, Fukuda M, Nakamura Y and Katagiri T: Involvement of kinesin family member $2 \mathrm{C} / \mathrm{mitotic}$ centromere-associated kinesin overexpression in mammary carcinogenesis. Cancer Sci 99: 62-70, 2008.

35. Chan SH, Yee Ko JM, Chan KW, Chan YP, Tao Q, Hyytiainen M, Keski-Oja J, Law S, Srivastava G, Tang J, Tsao SW, Chen H, Stanbridge EJ and Lung ML: The ECM protein LTBP-2 is a suppressor of esophageal squamous cell carcinoma tumor formation but higher tumor expression associates with poor patient outcome. Int J Cancer 129: 565-573, 2011.
36. Sathyanarayana UG, Maruyama R, Padar A, Suzuki M, Bondaruk J, Sagalowsky A, Minna JD, Frenkel EP, Grossman HB, Czerniak B and Gazdar AF: Molecular detection of noninvasive and invasive bladder tumor tissues and exfoliated cells by aberrant promoter methylation of laminin-5 encoding genes. Cancer Res 64: 1425-1430, 2004.

37. Senchenko VN, Krasnov GS, Dmitriev AA, Kudryavtseva AV, Anedchenko EA, Braga EA, Pronina IV, Kondratieva TT, Ivanov SV, Zabarovsky ER and Lerman MI: Differential expression of CHL1 gene during development of major human cancers. PLoS One 6: e15612, 2011.

38. do Carmo Avides M and Glover DM: Abnormal spindle protein, Asp, and the integrity of mitotic centrosomal microtubule organizing centers. Science 283: 1733-1735, 1999.

39. Cheeseman IM, Hori T, Fukagawa T and Desai A: KNL1 and the CENP-H/I/K complex coordinately direct kinetochore assembly in vertebrates. Mol Biol Cell 19: 587-594, 2008.

40. Hayward DG and Fry AM: Nek2 kinase in chromosome instability and cancer. Cancer Lett 237: 155-166, 2006.

41. Nakano I, Masterman-Smith M, Saigusa K, Paucar AA, Horvath S, Shoemaker L, Watanabe M, Negro A, Bajpai R, Howes A, Lelievre V, Waschek JA, Lazareff JA, Freije WA, Liau LM, Gilbertson RJ, Cloughesy TF, Geschwind DH, Nelson SF, Mischel PS, Terskikh AV and Kornblum HI: Maternal embryonic leucine zipper kinase is a key regulator of the proliferation of malignant brain tumors, including brain tumor stem cells. J Neurosci Res 86: 48-60, 2008.

42. Jeong H, Ryu YJ, An J, Lee Y and Kim A: Epithelial-mesenchymal transition in breast cancer correlates with high histological grade and triple-negative phenotype. Histopathology 60: E87-E95, 2012.

43. Horvath S, Zhang B, Carlson M, Lu KV, Zhu S, Felciano RM, Laurance MF, Zhao W, Qi S, Chen Z, Lee Y, Scheck AC, Liau LM, Wu H, Geschwind DH, Febbo PG, Kornblum HI, Cloughesy TF, Nelson SF and Mischel PS: Analysis of oncogenic signaling networks in glioblastoma identifies ASPM as a molecular target. Proc Natl Acad Sci USA 103: 17402-17407, 2006.

44. Moroi Y, Peebles C, Fritzler MJ, Steigerwald J and Tan EM: Autoantibody to centromere (kinetochore) in scleroderma sera. Proc Natl Acad Sci USA 77: 1627-1631, 1980

45. Tomonaga T, Matsushita K, Yamaguchi S, Oohashi T, Shimada H, Ochiai T, Yoda K and Nomura F: Overexpression and mistargeting of centromere protein-A in human primary colorectal cancer. Cancer Res 63: 3511-3516, 2003.

46. de la Guardia C, Casiano CA, Trinidad-Pinedo J and Báez A: CENP-F gene amplification and overexpression in head and neck squamous cell carcinomas. Head Neck 23: 104-112, 2001.

47. Grützmann R, Pilarsky C, Ammerpohl O, Lüttges J, Böhme A, Sipos B, Foerder M, Alldinger I, Jahnke B, Schackert HK, Kalthoff H,Kremer B,Klöppel G and Saeger HD: Gene expression profiling of microdissected pancreatic ductal carcinomas using high-density DNA microarrays. Neoplasia 6: 611-622, 2004.

48. Bièche I, Vacher S, Lallemand F, Tozlu-Kara S, Bennani H, Beuzelin M, Driouch K, Rouleau E, Lerebours F, Ripoche H, Cizeron-Clairac G, Spyratos F and Lidereau R: Expression analysis of mitotic spindle checkpoint genes in breast carcinoma: role of NDC80/HEC1 in early breast tumorigenicity, and a two-gene signature for aneuploidy. Mol Cancer 10: 23, 2011.

49. Hu Z, Huang G, Sadanandam A, Gu S, Lenburg ME, Pai M, Bayani N, Blakely EA, Gray JW and Mao JH: The expression level of HJURP has an independent prognostic impact and predicts the sensitivity to radiotherapy in breast cancer. Breast Cancer Res 12: R18, 2010. 